\title{
Design of Improved Integral Sliding Mode Observer for Surface-Mounted Permanent Magnet Synchronous Motor
}

Wei Liu ( $D$ 805280992@qq.com )

TGU: Tiangong University

\section{Li Zhang}

TGU: Tiangong University

\section{Guoying Ning}

TGU: Tiangong University

\section{Yi Cheng}

TGU: Tiangong University

\section{Guowei Xu}

TGU: Tiangong University

\section{Research Article}

Keywords: Surface-Mounted Permanent Magnet Synchronous Motor(SPMSM), Sliding Mode Oberver(SMO), Back electromotive force(back-EMF), Exponential reaching law

Posted Date: March 2nd, 2021

DOl: https://doi.org/10.21203/rs.3.rs-255740/v1

License: (c) (1) This work is licensed under a Creative Commons Attribution 4.0 International License. Read Full License 


\section{Design of Improved Integral Sliding Mode Observer for Surface- Mounted Permanent Magnet Synchronous Motor}

Wei Liu ${ }^{\mathrm{a}, \mathrm{b},{ }^{*}}$, Li Zhang ${ }^{\mathrm{a}}$, Guoying Ning ${ }^{\mathrm{c}}$, Yi Cheng ${ }^{\mathrm{c}}$, Guowei Xu ${ }^{\mathrm{c}}$

a School of Mechanical Engineering, Tiangong University, Tianjin 300387, China

${ }^{b}$ Advanced Mechatronics Equipment Technology Tianjin Area Major Laboratory, Tiangong University, Tianjin 300387, China

${ }^{c}$ School of Electrical Engineering and Automation, Tiangong University, Tianjin 300387, China

\section{A B S T R A C T}

An improved integral sliding mode observer (SMO) is proposed for the double closedloop control system of Surface-Mounted Permanent Magnet Synchronous Motor(SPMSM) in this paper. By observing the stator current, the extended back Electromotive Force(back-EMF)of the motor is estimated, and the position and angle of the rotor are obtained by using the Phase-Locked Loop (PLL) structure. The improved integrated SMO control system not only ensures the system to converge to the equilibrium point in finite time, but also reduces the steady-state error. A new exponential reaching law is also designed in which the $\operatorname{sgn}(\mathrm{s})$ of the constant velocity term is replaced by the sigmoid(s). For improving the reaching speed, the gain adaptive function is added to the exponential term of the approaching law to make its coefficient change with the system state. Simulation results compared with the traditional SMO show that the control system based on the improved SMO can reduce observation error, enhance robustness, and suppress chattering phenomenon.

Keywords: Surface-Mounted Permanent Magnet Synchronous Motor(SPMSM), Sliding Mode Oberver(SMO), Back electromotive force(back-EMF), Exponential reaching law.

\section{Introduction}

Surface-mounted permant magnet synchronous motor (SPMSM) is a kind of motor whose permanent magnet is made into tile and placed on the surface of rotor. It is widely used in various kinds of high-performance motion control because of its large torqueto-weight ratio, long service life and other advantages [1]. Generally, to get a high- 
precision and high-performance motor double closed-loop control system, accurate rotor position and speed must be obtained, so the sensors or encoders needs to be installed in the control system. However, the price of the sensor is expensive and the working environment are relatively strict so that the cost of motor is increased, the reliability is reduced and its application is limited [2]. The sensorless control based on motor model to obtain the position and speed overcomes a series of problems caused by the use of sensors. Consequently it has received extensive concerned [3, 4].

Since the back electromotive force (back-EMF) contains the rotor speed and position information, and its amplitude is large and easy to observe, so various back-EMF estimation methods based on the motor model have been proposed[5]. These methods are commonly used in middle and high speed control occasions, such as Nonlinear Observers [6, 7], Model Reference Adaptive Algorithms [8, 9], Extended Kalman Filter Algorithm [10, 11], Sliding Mode Observer Algorithm [12, 13]. Compared with above methods, Sliding Mode Observer (SMO) is a nonlinear and a variable structure control principle discontinuous control strategy, and it has been concerned by an increasing number of researchers because of its strong robustness to external disturbance, low sensitivity to parameters changes and good dynamic performance [14]. Due to the discontinuity of traditional SMO, a lot of noise signals are introduced into the observed back-EMF, which affects the performance of the observer [15]. In literature [16-18] the continuous smooth switching function is used to replace the discontinuous switching function which makes the boundary layer continuous weaken chattering. Meanwhile, by reducing the disadvantageous effects of chattering to improve the accuracy of position calculation, a low pass filter (LPF) with fixed or variable cut-off frequency was used to process the observed signals [19]. However, the inherent phase delay characteristics of the low-pass filter would cause errors between the actual and estimated values. Therefore, a speed-related position compensator was designed which makes it is difficult to implement the control system . In addition, some scholars have put forward many methods related to the law of reaching to reduce the influence of chattering and achieved positive control effects [20-22], but it is hard to select appropriate parameters. The higher order sliding mode control methods [23-25] are increasingly used in sensorless position control of SPMSM, which can eliminate chattering without reducing the robustness of the system. In [26], the rotor position and speed of SPMSM are obtained by combining SMO with super twisting algorithm (STA). It has high observation accuracy, good tracking effect and small chattering, but it needs 
to be assumed strictly, which increases the difficulty of theoretical verification. Moreover, the practical application is more complicated. Hence, other researchers have proposed a quasi-continuous high-order sliding mode control method in which the integral term was applied $[27,28]$. This control method is not only simple in structure, but also has small steady-state error and high control accuracy. However, its insufficient convergence speed affects the dynamic performance of the system.

Therefore, for realizing high precision and high performance double closed loop sensorless control of SPMSM, a high-order SMO is proposed in this paper. This observer adds the integral term of state variables in the traditional SMO and improved, which reducing the system steady-error and guarantee the system state converges to the equilibrium state in the limited time. The Lyapunov stability analysis proves the proposed SMO is stable. At the same time, by changing the coefficients of the switching term and exponential term, the new exponential reaching law can reduce the amplitude of the switching term, suppress chattering phenomenon, increase approaching the sliding mode surface of the reaching law rate, and shorten the time of reaching the sliding mode surface. Simulation results show that the proposed method can enhance the robustness of the control system.

\section{Mathematical model of PMSM}

The voltage equivalent circuit diagram of three-phase SPMSM is presented in Fig.1

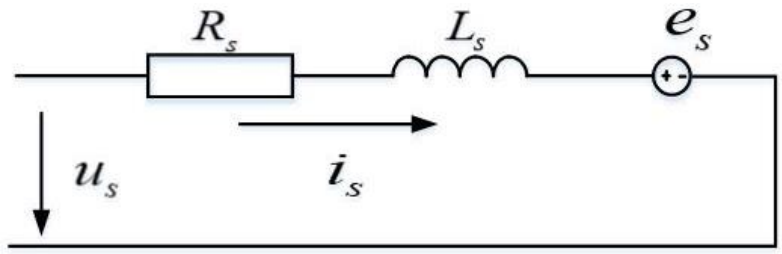

Fig. 1 The voltage equivalent circuit diagram of three-phase SPMSM

Assuming that SPMSM and meets the following conditions: (1) the motor saturation core, the eddy current and hysteresis loss are ignored; (2) the three-phase current is a sine wave current. The mathematical model of SPMSM is

$$
\left\{\begin{array}{l}
u_{\alpha}=R_{s}+L_{d} \frac{d i_{\alpha}}{d t}+e_{\alpha} \\
u_{\beta}=R_{s}+L_{q} \frac{d i_{\beta}}{d t}+e_{\beta}
\end{array}\right.
$$

where $u_{\alpha}, u_{\beta}, i_{\alpha}, i_{\beta}$ are the voltage and current, $R_{s}, L_{d}=L_{q}=L_{s}$ are the stator resistance and inductance, $e_{\alpha}$ and $e_{\beta}$ are the back-EMF. 
According to (1), the equation of stator current is

$$
\left\{\begin{array}{l}
\frac{d i_{\alpha}}{d t}=-\frac{R_{s}}{L_{s}} i_{\alpha}+\frac{1}{L_{s}} u_{\alpha}-\frac{1}{L_{s}} e_{\alpha} \\
\frac{d i_{\beta}}{d t}=-\frac{R_{s}}{L_{s}} i_{\beta}+\frac{1}{L_{s}} u_{\beta}-\frac{1}{L_{s}} e_{\beta}
\end{array}\right.
$$

In the actual working environment, the values of stator resistance and inductance will change with the increases of motor temperature, which will lead to the increase of system control error and affect the control system accuracy. So, the current equation can be obtained

$$
\left\{\begin{array}{l}
\frac{d i_{\alpha}}{d t}=-\frac{R_{s}+\Delta R_{s}}{L_{s}+\Delta L_{s}} i_{\alpha}+\frac{1}{L_{s}+\Delta L_{s}} u_{\alpha}-\frac{1}{L_{s}+\Delta L_{s}} e_{\alpha} \\
\frac{d i_{\beta}}{d t}=-\frac{R_{s}+\Delta R_{s}}{L_{s}+\Delta R_{s}} i_{\beta}+\frac{1}{L_{s}+\Delta L_{s}} u_{\beta}-\frac{1}{L_{s}+\Delta L_{s}} e_{\beta}
\end{array}\right.
$$

where $\Delta R_{s}$ and $\Delta L_{s}$ are the variation of motor resistance and inductance.

The back-EMF equation of the motor is

$$
\left\{\begin{array}{c}
e_{\alpha}=-\psi_{f} \omega \sin \theta \\
e_{\beta}=\psi_{f} \omega \cos \theta
\end{array}\right.
$$

where $\Psi_{f}$ is the stator flux linkage, $\omega$ is the angular velocity of the rotor, $\theta$ is rotor electrical angle. It can be seen from (4) that the back-EMF of the motor contains the actual rotor position and speed information, but these variables cannot be measured directly. So, it is indispensable to design observer to estimate the back-EMF.

\section{Design of sliding mode observer}

\subsection{Design of sliding mode surface}

To obtain the back-EMF of the motor, according to (2), the stator current observer is designed as follows

$$
\left\{\begin{array}{l}
\frac{d \hat{i}_{\alpha}}{d t}=-\frac{R_{s}}{L_{s}} \hat{i}_{\alpha}+\frac{1}{L_{s}} u_{\alpha}-\frac{1}{L_{s}} v_{\alpha} \\
\frac{d \hat{i}_{\beta}}{d t}=-\frac{R_{s}}{L_{s}} \hat{i}_{\beta}+\frac{1}{L_{s}} u_{\beta}-\frac{1}{L_{s}} v_{\beta}
\end{array}\right.
$$

where $\hat{i}_{\alpha}$ and $\hat{i}_{\beta}$ are the observed value of current, $v_{\alpha}$ and $v_{\beta}$ are the input function of the SMO.

Regardless of the motor temperature changes on the parameters of the motor, the 
stator current error equations is obtained from (2) and (5) as

$$
\left\{\begin{array}{l}
\frac{d \overline{i_{\alpha}}}{d t}=-\frac{R_{s}}{L_{s}} \bar{i}_{\alpha}+\frac{1}{L_{s}} e_{\alpha}-\frac{1}{L_{s}} v_{\alpha} \\
\frac{d \overline{i_{\beta}}}{d t}=-\frac{R_{s}}{L_{s}} \overline{i_{\beta}}+\frac{1}{L_{s}} e_{\beta}-\frac{1}{L_{s}} v_{\beta}
\end{array}\right.
$$

where $\bar{i}_{\alpha}=\hat{i}_{\alpha}-i_{\alpha}$ and $\bar{i}_{\beta}=\hat{i}_{\beta}-i_{\beta}$ are the estimation error of the current.

For the convenience of subsequent analysis, (6) is written in the following vector form:

$$
\dot{\overline{i_{s}}}=-\frac{R_{s}}{L_{s}} \overline{i_{s}}+\frac{1}{L_{s}} e_{s}-\frac{1}{L_{s}} v_{s}
$$

where $\bar{i}_{s}=\left[\begin{array}{ll}\bar{i}_{\alpha} & \bar{i}_{\beta}\end{array}\right]^{\mathrm{T}}$ is the current estimation error column vector, $e_{s}=\left[\begin{array}{ll}e_{\alpha} & e_{\beta}\end{array}\right]^{\mathrm{T}}$ is the back-EMF column vector, $v_{s}=\left[\begin{array}{ll}v_{\alpha} & v_{\beta}\end{array}\right]^{\mathrm{T}}$ is the control input column vector of the observer.

Lemma: assuming a second-order differential equation $\ddot{y}+m \dot{y}+n y=0$ and there are two unequal real roots $r_{1}$ and $r_{2}$, the solution of the differential equation is $y=\lambda_{1} e^{r_{1} t}+\lambda_{2} e^{r_{2} t}$. It is known that $y(0)$ and $\dot{y}(0), \lambda_{1}$ and $\lambda_{2}$ are solved and the sign of them are opposite. When $y\left(t_{s}\right)=0$, the solution is $t_{s}=\ln \left(-\lambda_{2} / \lambda_{1}\right) /\left(r_{1}-r_{2}\right)$.

To improve the tracking effect of the observer and enable the system to converge to the equilibrium state in the limited time, the SMO is designed as follows:

$$
s_{s}=c_{1} \overline{i_{s}}+c_{2} \int_{0}^{t} \overline{i_{s}} d \tau+c_{3} \dot{\overline{i_{s}}}
$$

where $s_{s}=\left[\begin{array}{ll}s_{\alpha} & s_{\beta}\end{array}\right]^{T}, c_{1}>0, c_{2}>0, c_{3}>0$. By applying the integral term of the state variable in the SMO, the steady-state error is reduced and the SMO can guarantee the system state converges to equilibrium state in the limited time.

When the system from any initial state $s_{s}(0) \neq 0$ reaches to the sliding surface at time $t_{1}$

$$
\begin{gathered}
s_{s}\left(t_{1}\right)=0 \\
\dot{\overline{i_{s}}}=-\frac{c_{1}}{c_{3}} \overline{i_{s}}-\frac{c_{2}}{c_{3}} \int_{0}^{t} \overline{i_{s}} d \tau
\end{gathered}
$$

The time derivative of the (8) is: 


$$
\dot{s}_{s}=c_{1} \dot{\overline{i_{s}}}+c_{2} \overline{i_{s}}+c_{3} \ddot{\bar{i}_{s}}
$$

Proof: when the system reaches the sliding surface from any initial state, according to the (9) and (10) can be obtained:

$$
\begin{gathered}
\dot{s}_{s}\left(t_{1}\right)=0 \\
\ddot{\overline{i_{s}}}+\frac{c_{1}}{c_{3}} \dot{\overline{i_{s}}}+\frac{c_{2}}{c_{3}} \overline{i_{s}}=0
\end{gathered}
$$

When $c_{1}^{2}>4 c_{2} c_{3}$, from (13)

$$
\left\{\begin{array}{l}
r_{1}=\frac{-c_{1}+\sqrt{c_{1}^{2}-4 c_{2} c_{3}}}{2 c_{3}} \\
r_{2}=\frac{-c_{1}-\sqrt{c_{1}^{2}-4 c_{2} c_{3}}}{2 c_{3}}
\end{array}\right.
$$

So

$$
\overline{i_{\mathrm{s}}}=\lambda_{1} \exp \left(\frac{-c_{1}+\sqrt{c_{1}^{2}-4 c_{2} c_{3}}}{2 c_{3}} t\right)+\lambda_{2} \exp \left(\frac{-c_{1}-\sqrt{c_{1}^{2}-4 c_{2} c_{3}}}{2 c_{3}} t\right)
$$

Known $\bar{i}_{s}\left(t_{1}\right) \neq 0$ and $\dot{\dot{i}_{s}}\left(t_{1}\right)=-\frac{c_{1}}{c_{3}} \bar{i}_{s}\left(t_{1}\right)$, hence

$$
\left\{\begin{array}{l}
\lambda_{1}=\frac{-c_{1}+\sqrt{c_{1}^{2}-4 c_{2} c_{3}}}{2 \sqrt{c_{1}^{2}-4 c_{2} c_{3}}} \bar{i}_{s}\left(t_{1}\right) \\
\lambda_{2}=\frac{c_{1}+\sqrt{c_{1}^{2}-4 c_{2} c_{3}}}{2 \sqrt{c_{1}^{2}-4 c_{2} c_{3}}} \bar{i}_{s}\left(t_{1}\right)
\end{array}\right.
$$

When the state variables of the system reach the sliding surface converge to the equilibrium point after the time $t_{s}$ :

$$
\bar{i}_{s}\left(t_{s}\right)=\lambda_{1} \exp \left(\frac{-c_{1}+\sqrt{c_{1}^{2}-4 c_{2} c_{3}}}{2 c_{3}} t_{s}\right)+\lambda_{2} \exp \left(\frac{-c_{1}-\sqrt{c_{1}^{2}-4 c_{2} c_{3}}}{2 c_{3}} t_{s}\right)=0
$$

So

$$
t_{s}=\frac{\ln \left(-\left(c_{1}+\sqrt{c_{1}^{2}-4 c_{2} c_{3}}\right) /\left(-c_{1}+\sqrt{c_{1}^{2}-4 c_{2} c_{3}}\right)\right)}{\sqrt{c_{1}^{2}-4 c_{2} c_{3}} / c_{3}}
$$

Thus, the system state can reach the equilibrium point in finite time.

\subsection{Improvement of the reaching law}


To further enhance the characteristics of the traditional exponential reaching law, the system dynamic performance and weaken chattering phenomenon, a new exponential reaching law is proposed as

$$
\dot{s}=-k_{1} g(s)-k_{2}|s|^{\varphi s g n(|s|-a)} s
$$

Among them

$$
g(s)=\frac{1-e^{-c s}}{1+e^{c s}}
$$

where $s$ represents sliding surface, $k_{1}>0, k_{2}>0, c>0,0<\varphi<1$ and $a>0$.

In the equation of reaching law, the continuous hyperbolic tangent function $g(s)$ is used to replace the $\operatorname{sgn}(s)$ of constant velocity term, and the variable gain term $k_{2}|s|^{\gamma s g n(|s|-a)} s$ is introduced into the exponential term.

According to the analysis of (19), when the system state is far away from the sliding surface, then, $k_{2}|s|^{\varphi s g n(|s|-a)} s>k_{2} s$, the approach speed of the system to the sliding surface is accelerated and the motion time is shortened. When the system state is approached the sliding surface, the exponential term coefficient is almost zero and mainly the $g(s)$ in the constant velocity term plays a role. By using the hyperbolic tangent function $g(s)$ instead of the $\operatorname{sgn}(s)$, the amplitude of switching function is reduced. So, the new reaching law can improve the approach speed and reduce chattering effectively.

\subsection{Proof of stability}

The time derivative of the (7) is:

$$
\ddot{\overrightarrow{i_{s}}}=-\frac{R_{s}}{L_{s}} \dot{\overline{i_{s}}}+\frac{1}{L_{s}} \dot{e}_{s}-\frac{1}{L_{s}} \dot{v}_{s}
$$

Comprehensive (7)-(9) analysis, the sliding mode control law is designed as follows:

$$
v_{s}=-R_{s} \bar{i}_{s}+\int\left(L_{s} \frac{c_{1}}{c_{3}} \dot{\bar{i}}_{s}+L_{s} \frac{c_{2}}{c_{3}} \bar{s}_{s}+k_{1} g\left(s_{s}\right)+k_{2}\left|s_{s}\right|^{\operatorname{\rho sgn}(|s|-a)} s_{s}\right) d \tau
$$

Define the Lyapunov function

$$
V=\frac{1}{2} s_{s}^{T} s_{s}
$$

The time derivative of the (23) 


$$
\begin{aligned}
\dot{V} & =s_{s}^{T} \dot{s}_{s}=s_{s}^{T}\left(c_{1} \dot{\bar{i}_{s}}+c_{2} \bar{i}_{s}+c_{3} \ddot{\ddot{i}_{s}}\right) \\
& =\left(\frac{1}{L_{s}} \dot{e}_{\alpha} s_{\alpha}+\frac{1}{L_{s}} \dot{e}_{\beta} s_{\beta}-\frac{1}{L_{s}} k_{1} g\left(s_{\alpha}\right) s_{\alpha}-\frac{1}{L_{s}} k_{1} g\left(s_{\beta}\right) s_{\beta}\right)-\left(\frac{1}{L_{s}} k_{2}\left|s_{\alpha}\right|^{\operatorname{ssg} n\left(\left|s_{\alpha}\right|-a\right)} s_{\alpha}^{2}+\frac{1}{L_{s}} k_{2}\left|s_{\beta}\right|^{\rho s g n n\left(\left|s_{\beta}\right|-a\right)} s_{\beta}^{2}\right)
\end{aligned}
$$

To stabilize the proposed observer, then $\dot{V}<0$

$$
\dot{V} \leq\left(\frac{1}{L_{s}}\left(\left|\dot{e}_{\alpha}\right|-k_{1}\right)\left|s_{\alpha}\right|+\frac{1}{L_{s}}\left(\left|\dot{e}_{\beta}\right|-k_{1}\right)\left|s_{\beta}\right|\right)-\left(\frac{1}{L_{s}} k_{2}\left|s_{\alpha}\right|^{\mid \operatorname{ssg} n\left(\left|s_{\alpha}\right|-a\right)} s_{\alpha}^{2}+\frac{1}{L_{s}} k_{2}\left|s_{\beta}\right|^{\left.|s s n n| s_{\beta} \mid-a\right)} s_{\beta}^{2}\right)<0
$$

Assume $\left|\dot{e}_{s}\right| \leq M, M>0$, As long as $k_{1}>M$

$$
\dot{V}<-\left(\frac{1}{L_{s}} k_{2}\left|s_{\alpha}\right|^{\varphi s g n\left(\left|s_{\alpha}\right|-a\right)} s_{\alpha}^{2}+\frac{1}{L_{s}} k_{2}\left|s_{\beta}\right|^{\rho s g n\left(\left|s_{\beta}\right|-a\right)} s_{\beta}^{2}\right)<0
$$

Thus, the stability of the system can be proved.

\section{Rotor position and speed estimation}

To get the position and speed of the rotor of the motor, the arc tangent function method is usually used that is $\hat{\theta}=\tan ^{-1}\left(-\hat{e}_{\alpha} / \hat{e}_{\beta}\right)$. The calculation accuracy of this method is undeveloped and the error is large. So, PLL structure is used to obtain the rotor speed by PI regulating the errors of observing back-EMF $\hat{e}_{\alpha}$ and $\hat{e}_{\beta}$, and obtain the rotor angle can be obtained by integrating the speed. The structure diagram of PLL is shown as in Fig.2.

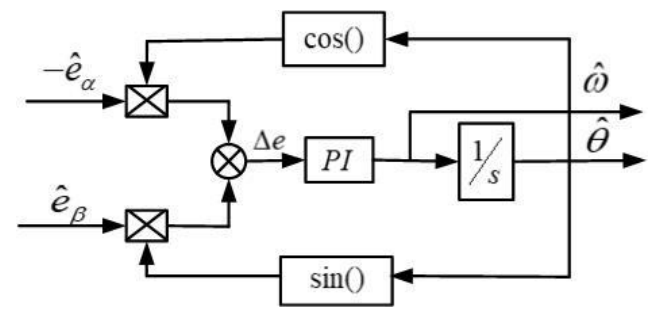

Fig.2. Block diagram of the PLL

According to the PLL structure in Fig.2:

$$
\Delta e=-\hat{e}_{\alpha} \cos \hat{\theta}-\hat{e}_{\beta} \sin \hat{\theta}=K \sin \theta \cos \hat{\theta}-K \cos \hat{\theta} \sin \theta=K \sin (\theta-\hat{\theta})
$$

where $\theta$ is actual rotor position angle output by the motor, $\hat{\theta}$ is the rotor position angle output by the phase-locked loop, $K=\hat{\omega} \psi_{f}$. When the electrical angle error is small enough, $\sin (\theta-\hat{\theta}) \approx \theta-\hat{\theta}$.

From (27), the PI module is expended and Fig.2 is simplified into Fig.3 to realize the tracking of $\hat{\theta}$ to $\theta$. The equivalent structure diagram of the PLL is shown in Fig.3. 


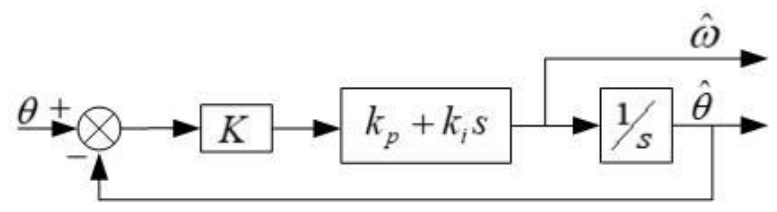

Fig.3 Equivalent structure diagram of the PLL

The transfer function from $\hat{\theta}$ to $\theta$ in Fig.2 is

$$
\left\{\begin{array}{l}
G_{c}(s)=\frac{K k_{p} s+K k_{i}}{s^{2}+K k_{p} s+K k_{i}} \\
G_{o}(s)=\frac{s^{2}}{s^{2}+K k_{p} s+K k_{i}}
\end{array}\right.
$$

\section{Simulation results and analysis}

In order to verify the robustness and accuracy of the proposed method, a position sensorless control simulation model of SPMSM needs to be esdablished. In the vector control system of SPMSM, PI control algorithm is used for current loop and speed loop, the rotor position and speed are obtained from the extended back-EMF of the observer by using the PLL of the position loop. The mainly steps of the control system are concluded as follows: (1) using coordinate transformation to decouple SPMSM; (2) using double closed-loop control of speed and current of SPMSM; (3) realization of space vector modulation (SPMSM); (4) obtaining rotor position and speed by sliding mode observer and PLL structure.

Table 1 The main parameters of SPMSM

\begin{tabular}{cccc}
\hline Prameter & Value & Prameter & Value \\
\hline$R_{S}$ & $2.875 \Omega$ & $U_{D C}$ & $300 \mathrm{~V}$ \\
$L_{S}$ & $2.85 \mathrm{mH}$ & $n_{N}$ & $600 \mathrm{r} / \mathrm{min}$ \\
$\psi_{f}$ & $0.175 \mathrm{~Wb}$ & $p_{n}$ & 4 \\
$J$ & $0.0003 \mathrm{~kg} \cdot \mathrm{m}^{2}$ & $c_{1}$ & 1 \\
$c_{2}$ & 1 & $c_{3}$ & 0.01 \\
$k_{1}$ & 500000 & $k_{2}$ & 10000 \\
\hline
\end{tabular}

SPMSM sensorless double closed-loop control system simulation model was established on MATLAB/Simulink platform as shown Fig.4 and compared with the traditional SMO. The main parameters of SPMSM are shown in Table 1. Sampling time $T_{s}=5 \times 10^{-7} \mathrm{~s}$, and simulation time $t=0.6 \mathrm{~s}$. 


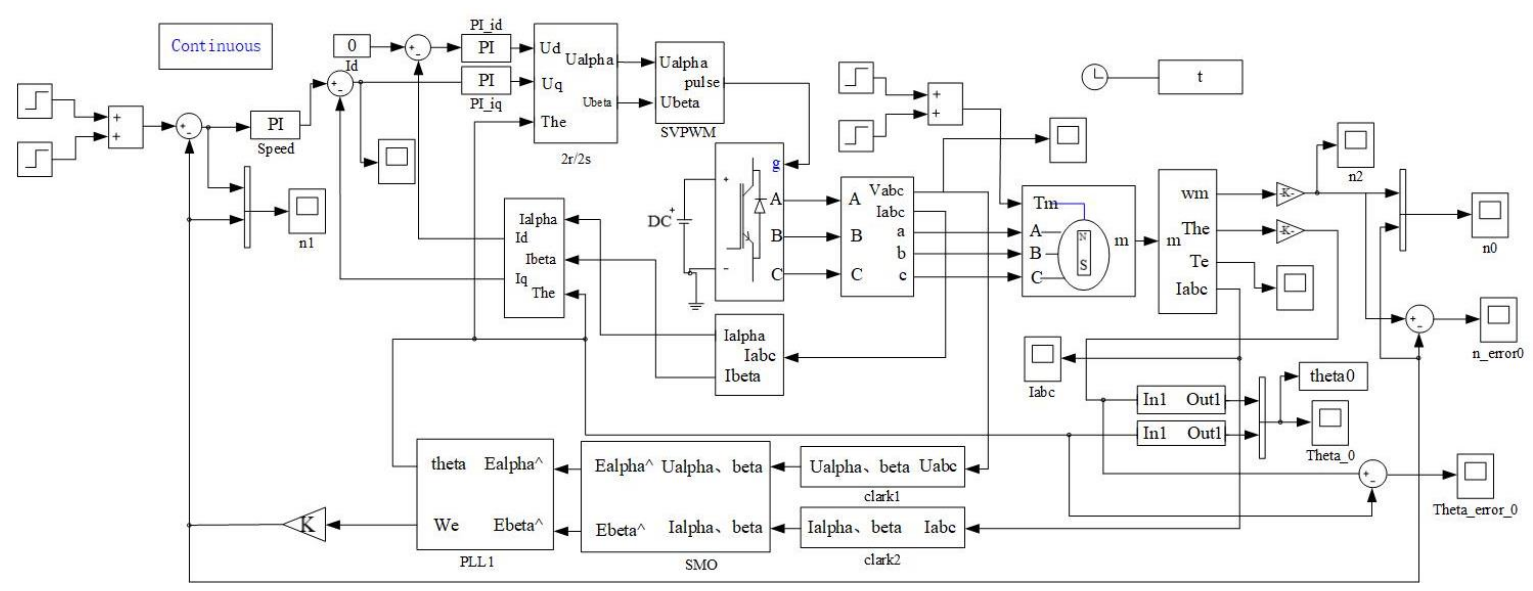

Fig.4 Simulation model of sliding mode observer system for SPMSM

Simulation conditions:the reference speed is $600 \mathrm{r} / \mathrm{min}$ without load torque and simulation time is $0.6 \mathrm{~s}$. As can be seen from Fig.5 (a) and (b) that both observers can observe the back-EMF of the motor very well. Fig.6 (a) and (b) show that when the SPMSM speed rises from zero to the reference speed and stable operation, two observers can quickly respond to the system and stabilize at reference speed. The partial enlarged view shows that the maximum speed of high-order SMO is $680 \mathrm{r} / \mathrm{min}$ and traditional SMO is $690 \mathrm{r} / \mathrm{min}$, when the system reaches the reference speed and maintain steady-state, the observer speed of the traditional SMO is not stable at the reference speed which frequently shuttles up and down around the reference, but the high-order SMO can be well stabilized at the reference speed without chattering and maintain the

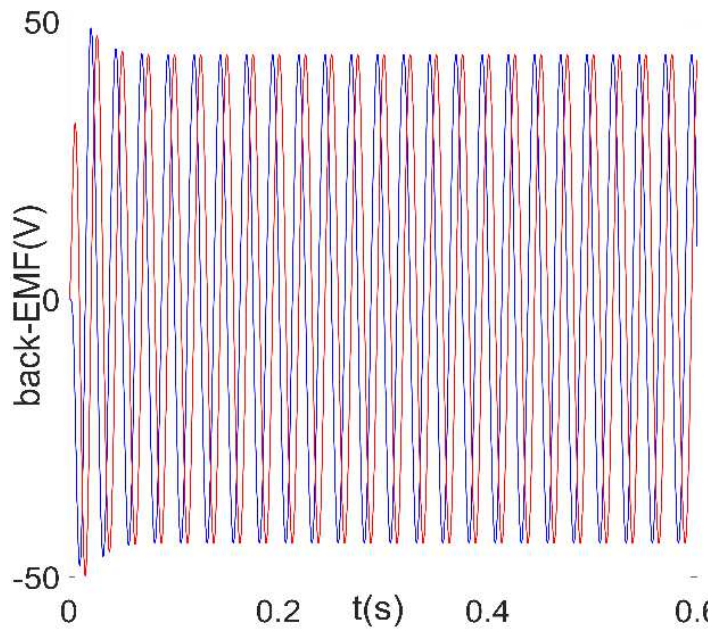

(a) The back-EMF of high-order SMO

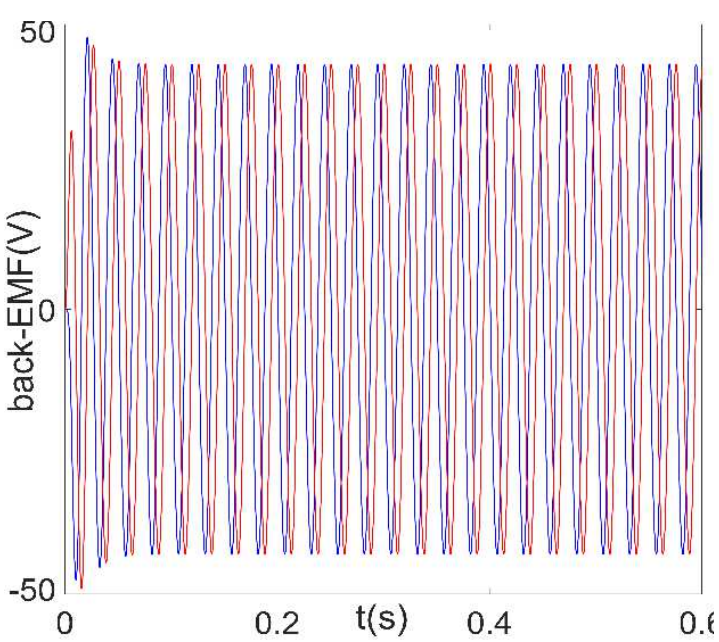

(b) the back-EMF of traditional SMO

Fig.5 Tracking performance of two SMOs (No load torque)

good dynamic response characteristics. Fig.7 (a) and (b) are the position tracking effect diagrams of the traditional SMO and high-order SMO. From the partial enlarged views, the position errors of the two observers are very large when the motor is just started. 
But as the simulation proceeds, the position errors are gradually decreases and tends to be stable. At the end of the simulation, the traditional SMO has a obvious phase lag between the actual value and the estimated value, while the high-order SMO is basically consistent with the actual value, and the error is almost zero.

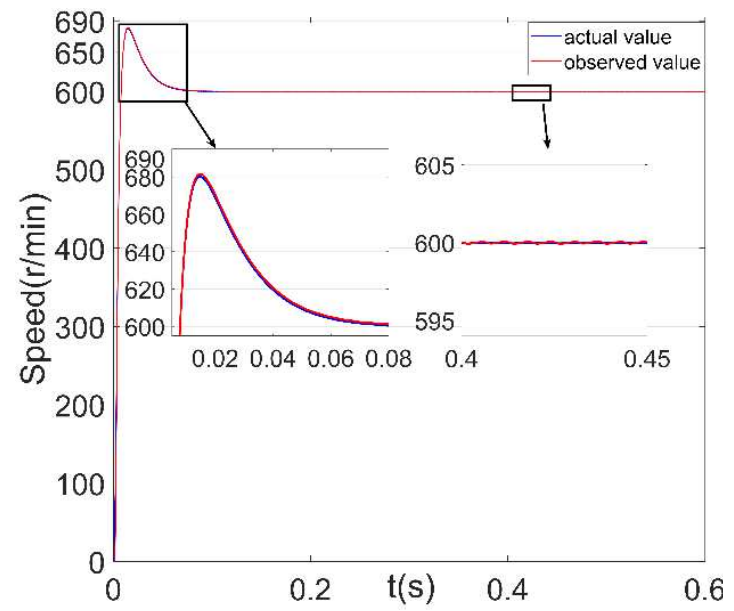

(a) speed tracking of high-order SMO

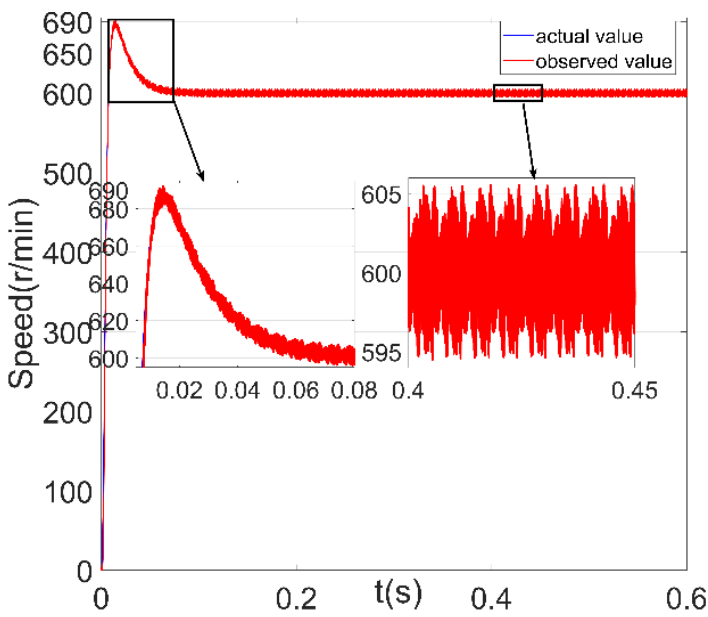

(b) speed tracking of traditional SMO

Fig.6 Speed tracking performance of two SMOs (No load torque)

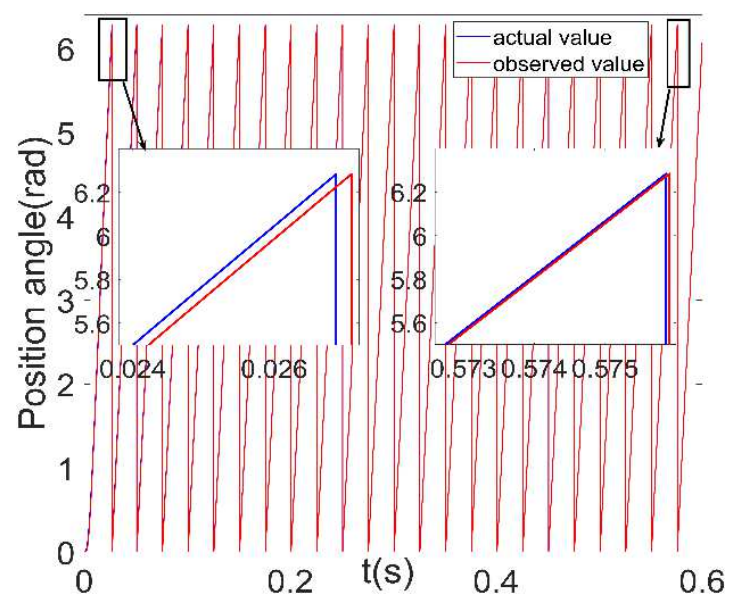

(a) position tracking of high-order SMO

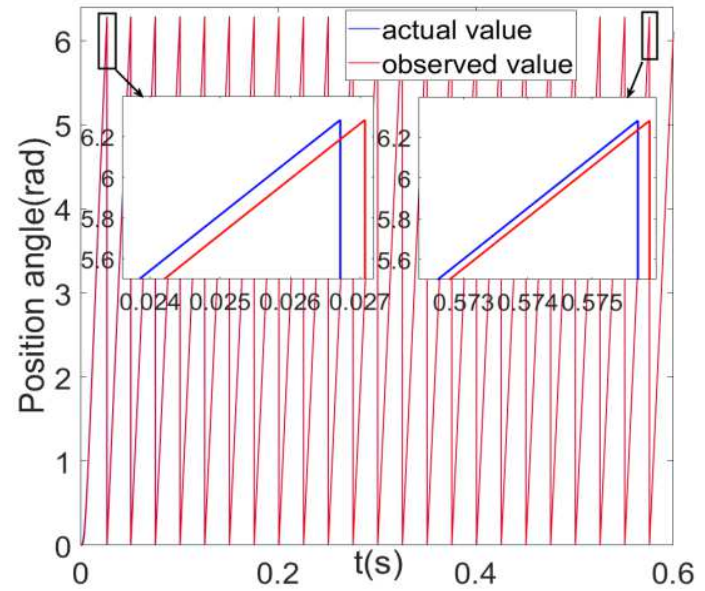

(b) position tracking of traditional SMO

Fig.7 Tracking performance of two SMOs (No load torque)

Simulation conditions: load torque and simulation time remain unchanged, the reference speed is changed as follows: the initial value is $600 \mathrm{r} / \mathrm{min}$. then rises to $800 \mathrm{r} / \mathrm{min}$ at $t=0.2 \mathrm{~s}$, finally, it rises to $1000 \mathrm{r} / \mathrm{min}$ at $t=0.4 \mathrm{~s}$. As shown in Fig.8 (a) and (b), when the motor speed increases, the back-EMF amplitude of the motor also increases. However, as shown in (b), after $0.4 \mathrm{~s}$, the back-EMF waveform of the motor after $0.4 \mathrm{~s}$ is not a sine wave and the waveform is distorted. Fig.9 is the motor speed tracking waveform. From Fig.9(a), as the speed increases, the overshoot and the time to reach the reference speed are gradually decreased, observed value can be well tracked to the actual value during the whole process. But from (b) we can be seen that within 
the range of simulation time $0 \sim 0.4 s$, the observed value can track the actual value and stabilize to the reference. The control system is stable despite the chattering. However, when the reference speed is rises from $800 \mathrm{r} / \mathrm{min}$ to $1000 \mathrm{r} / \mathrm{min}$, the switching amplitude of the observed speed is increased sharply, which makes the observed value unable to track the actual value and stabilize to the reference which seriously damages the stability of the system. The three-phase current tracking waveform of the motor show that although the three-phase current fluctuates considerably at the moment of speed change, it will soon return to stability and the current of the traditional SMO becomes disordered and the waveform is disorderly after $0.4 \mathrm{~s}$.

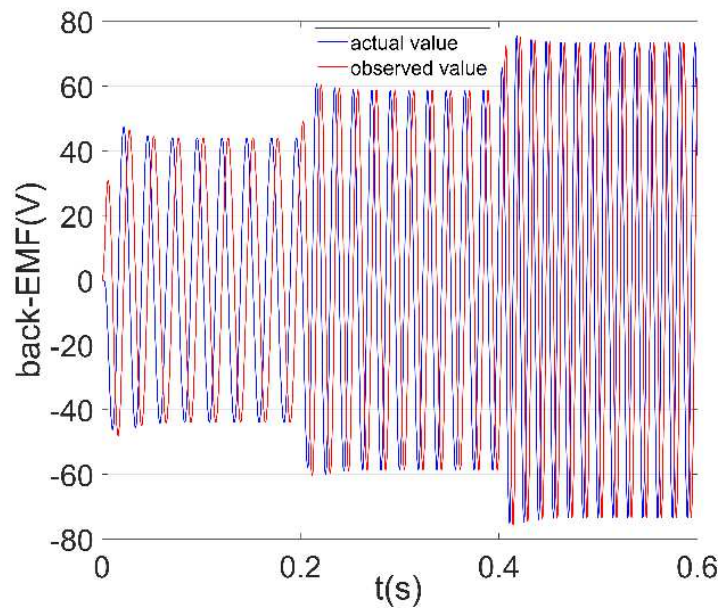

(a) back-EMF of high-order SMO

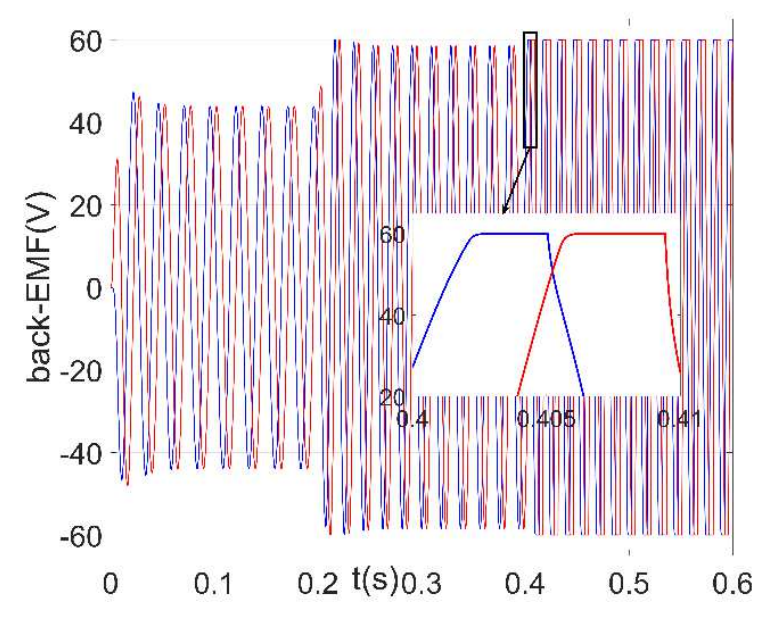

(b) back-EMF of traditional SMO

Fig.8 Back-EMF tracking of two SMOs(Speed step up)

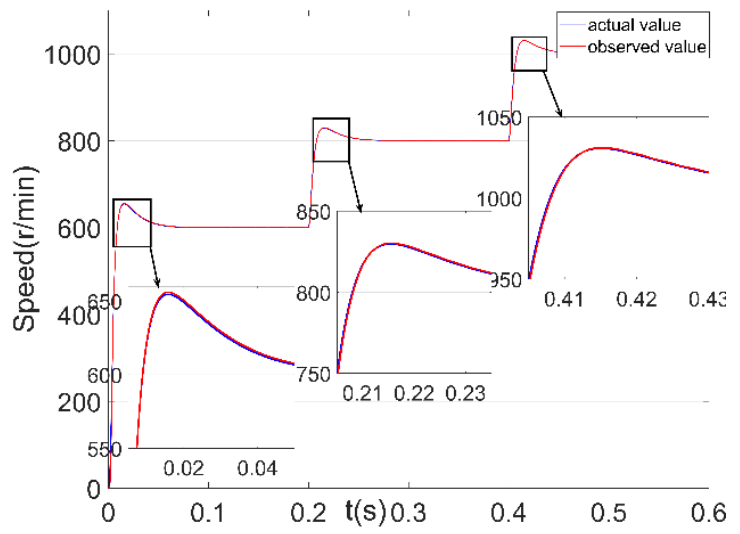

(a) Speed tracking of high-order SMO

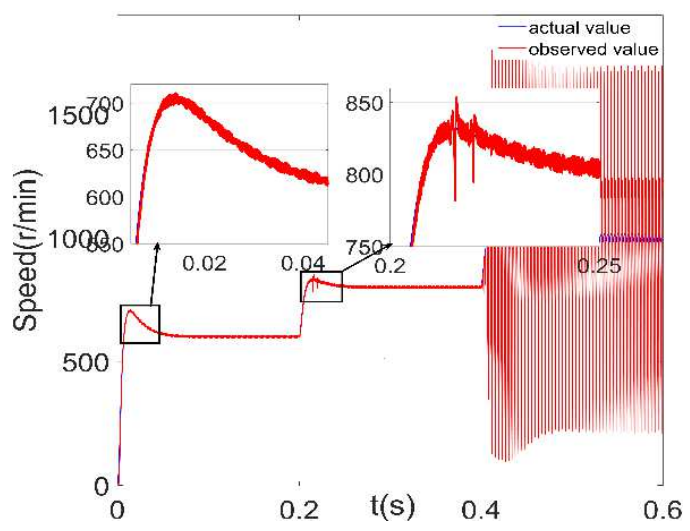

(b) Speed tracking of traditional SMO

Fig.9 Speed tracking of two SMOs(Speed step up)

The reference speed changes as follows:the initial value is $600 \mathrm{r} / \mathrm{min}$, then drops to $400 \mathrm{r} / \mathrm{min}$ at $t=0.2 \mathrm{~s}$, finally, drops to $200 \mathrm{r} / \mathrm{min}$ at $t=0.4 \mathrm{~s}$. Fig.10 shows the speed dynamic response diagrams of the two observers. During the speed changes, the observation can track the actual value, and the overshoot and the time that stabilize to 
the reference are also gradually decreasing. The chattering of the traditional SMO has also become smaller, but is still obvious. The high-order SMO has a slight chattering at reference speed of $200 \mathrm{r} / \mathrm{min}$, but does not affect the performance of the system. No matter the reference speed of the motor is increased or decreased, the high-order SMO can always maintain good dynamic tracking performance.

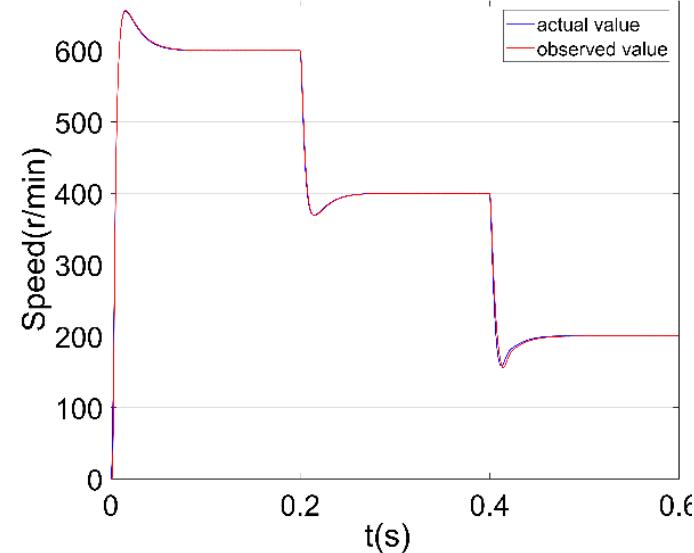

(a) Speed tracking of high-order SMO

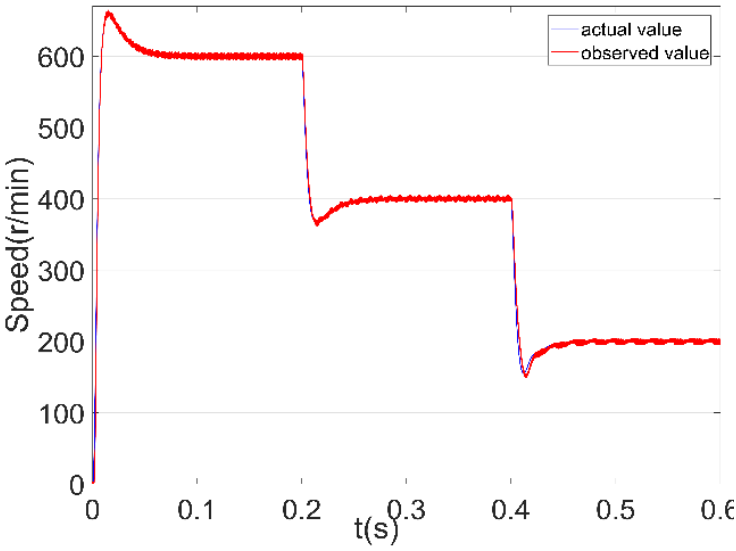

(b) Speed tracking of traditional SMO

Fig.10 Speed tracking of two SMOs(Speed step down)

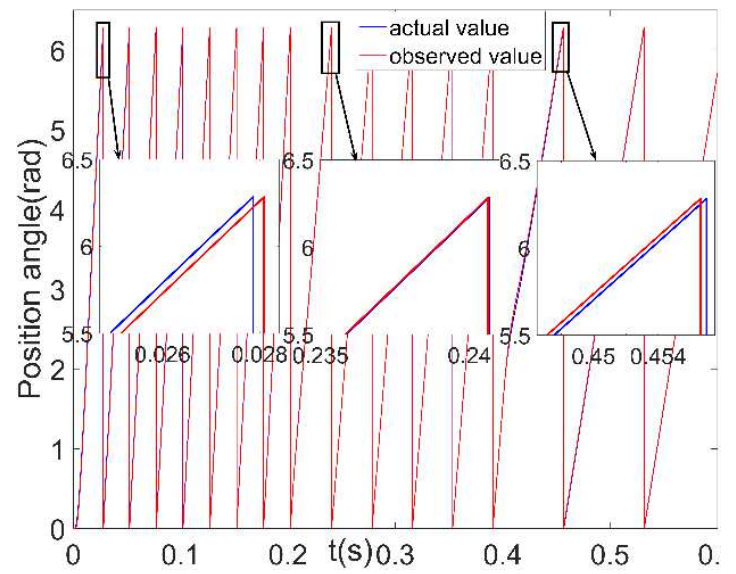

(a) Position of high-order SMO

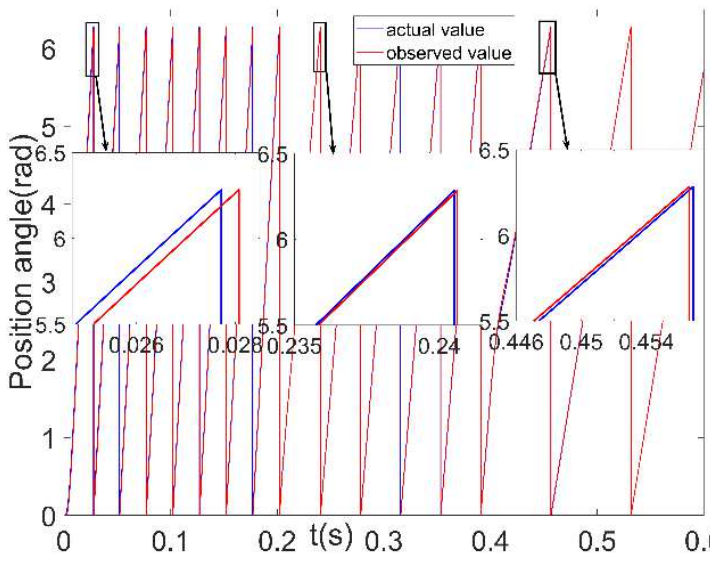

(b) Position tracking of traditional SMO

Fig.11 Position tracking of two SMOs(Speed step down)

Simulation conditions: the reference speed and simulation time remain unchanged, the load torque is given as follows: first, the load torque is $2 \mathrm{~N} \cdot \mathrm{m}$, then increases to $4 \mathrm{~N} \cdot \mathrm{m}$ at $t=0.2 \mathrm{~s}$ finally decreases to $0 \mathrm{~N} \cdot \mathrm{m}$ at $t=0.4 \mathrm{~s}$. Fig. 12 shows the electromagnetic torque of the two observers can track the change of the load torque. Fig.13 is the motor speed tracking waveform, when the load torque is increased suddenly, the speed of the motor will be decreased. The speed of high-order SMO will be dropped to $575 \mathrm{r} / \mathrm{min}$, while that of traditional SMO will be dropped to $570 \mathrm{r} / \mathrm{min}$. When the load torque is decreases suddenly, the speed of the motor will be increased, the high-order SMO will be increased to $645 \mathrm{r} / \mathrm{min}$, the traditional SMO will be increased to $650 \mathrm{r} / \mathrm{min}$. Whether the 
load torque is increased or reduced suddenly, both observers can quickly return to the reference and run stably after a short period of adjustment. The speed of the traditional SMO is varied greatly with the changes of load torque, while the high-order SMO is less. The motor position error waveform shows that the sudden change of the motor load torque will have an impact on the motor position error, but it has no impact on the final error.

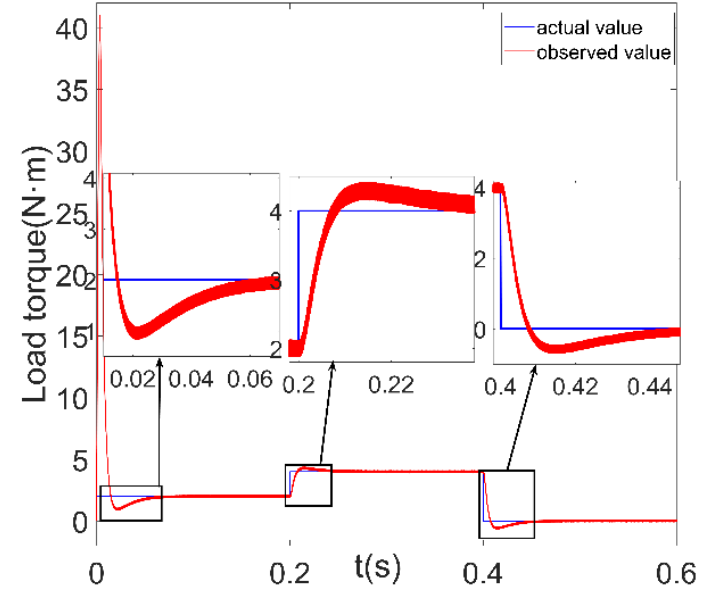

(a) Load torque of high-order SMO

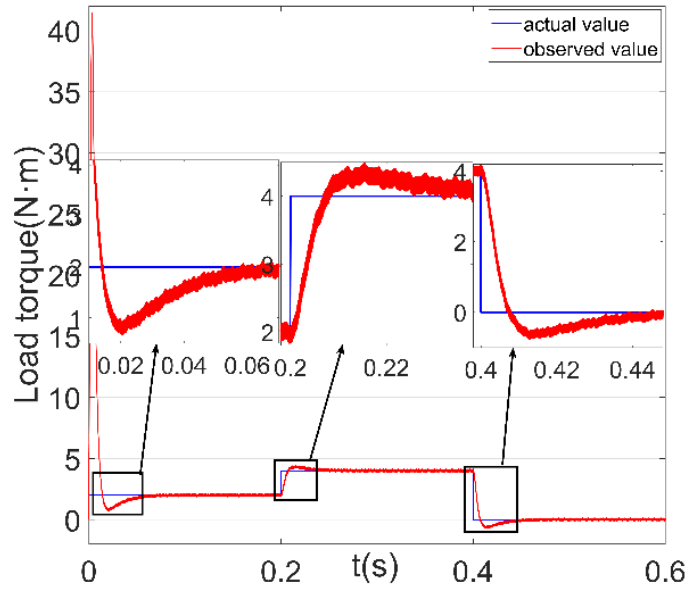

(b) Load torque of traditional SMO

Fig.12 Tracking performance of two SMO(Load torque)

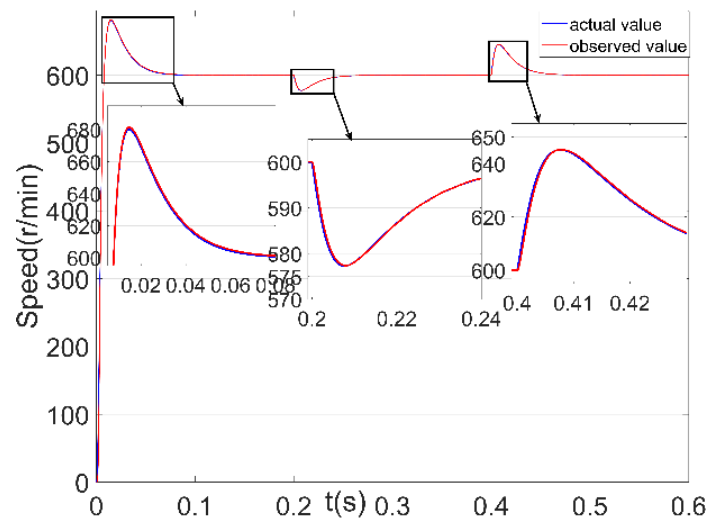

(a) Speed tracking of high-order SMO

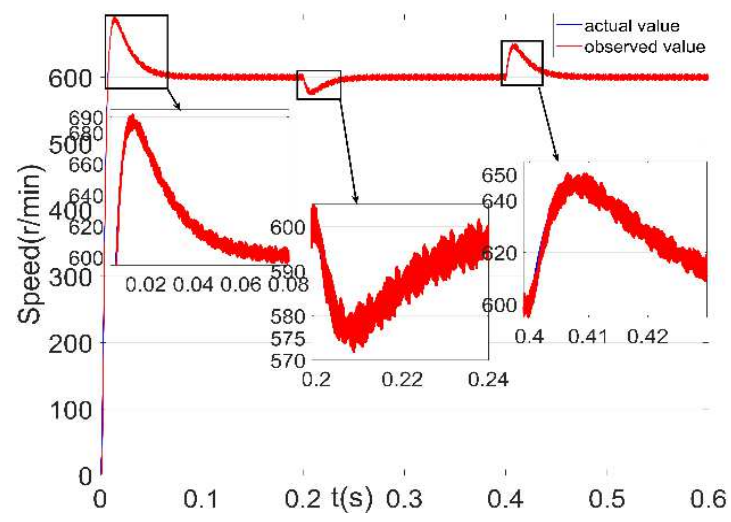

(b) Speed tracking of traditional SMO

Fig.13 Speed tracking performance of two SMO(Load torque)

Simulation conditions: reference speed is $250 \mathrm{r} / \mathrm{min}$, load torque is $2 N \cdot m$, the nominal value of resistance is uncertain. Tracking performance diagrams of high-order SMO under the resistance varying conditions of the SPMSM is show in Fig.15 and Fig.16. Fig.15 is the performance waveforms diagrams of $R_{S}=4.3125 \Omega$, Fig. 16 is the performance waveforms diagrams of $R_{s}=1.4375 \Omega$, It can be seen that no matter the resistance value is increased or decreased, there is the chattering phenomenon in the observed waveforms. When the speed rises from zero to the reference, the estimation error has a large value in the start-up stage, but the speed error is decreased gradually with the increase of the speed and stable operation. The reason for the increase of 
chattering and speed estimate error are that the resistance value is inconsistent before and after, which makes the upper limit of the disturbance changed, leading to slow response of the observer to the system and unable to track the actual value, thus increasing the speed error and reducing the observation effects, but not destroying the stability of the system. The estimated position angle can track the actual position angle of the motor well, and the position error remains unchanged.

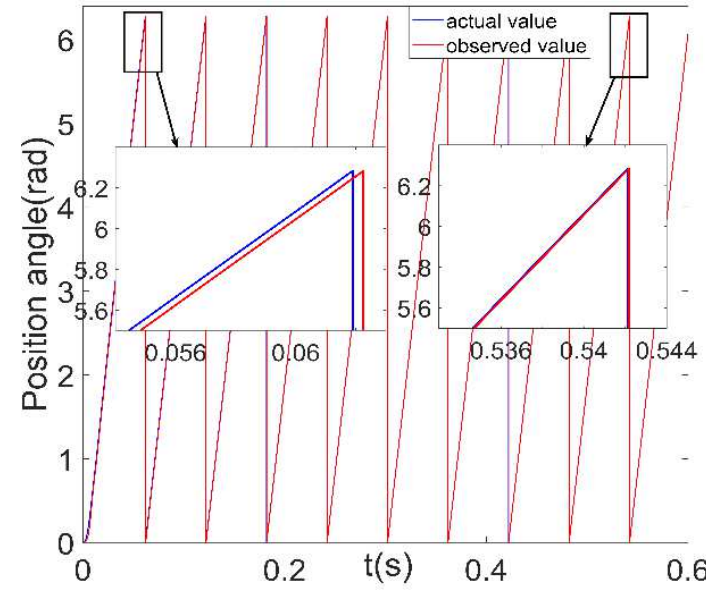

(a) Position tracking $\left(R_{s}=4.3125 \Omega\right)$

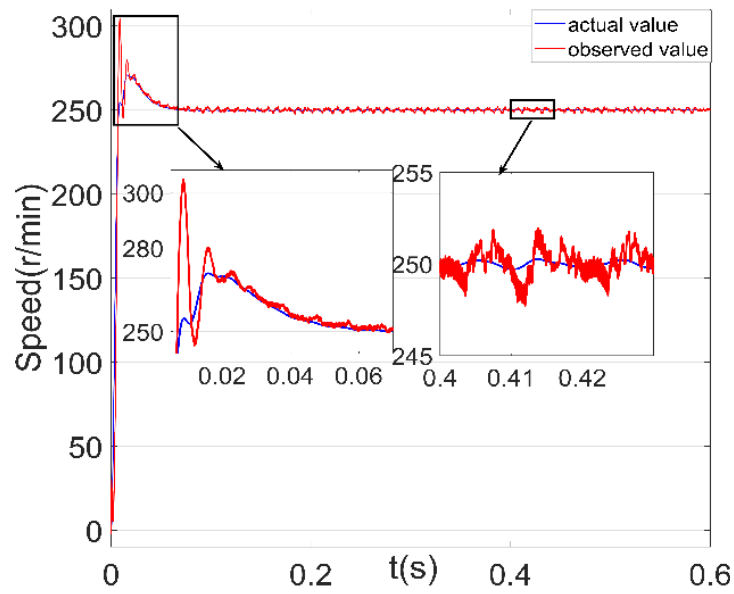

(b) Speed tracking $\left(R_{s}=4.3125 \Omega\right)$

Fig.15 Tracking performance of high-order SMO(resistance increase)

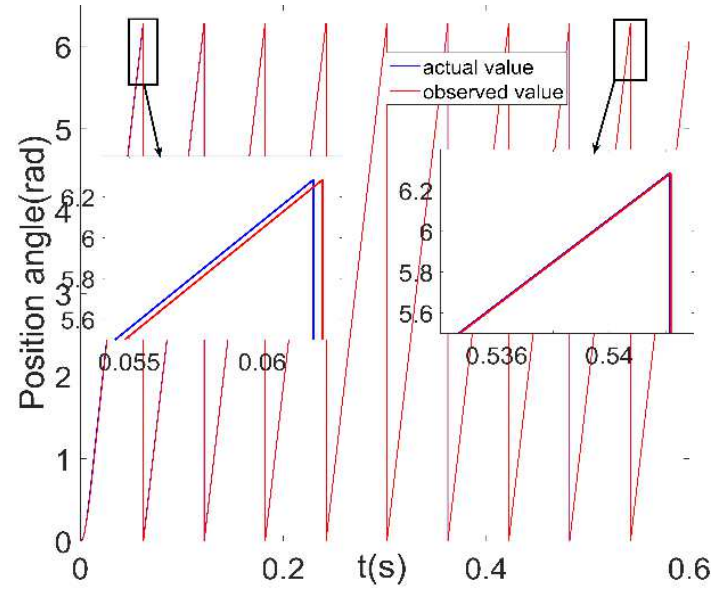

(a) Position tracking $\left(R_{s}=1.4375 \Omega\right)$

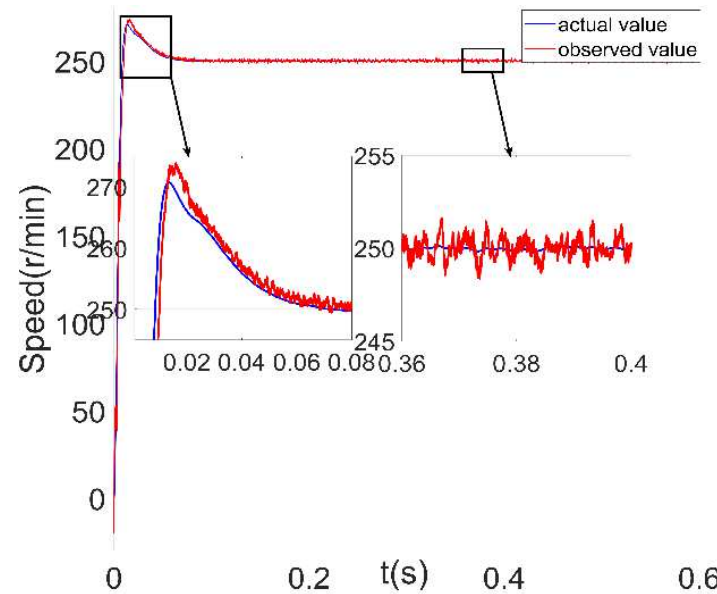

(b) Speed tracking $\left(R_{s}=1.4375 \Omega\right)$

Fig.16 Tracking performance of high-order SMO(resistance decreases)

\section{Conclusion}

In this paper, an improved exponential reaching law combined with improved integral SMO control is proposed for sensorless control of SPMSM double closed-loop position control. The back-EMF of the SPMSM is estimated by the proposed high-order SMO design stator current observer, and the estimated rotor position and rotational speed are obtained. A new exponential reaching law is proposed, in which the 
continuous smooth switching function is used to replace the discontinuous sign function in the constant speed term and the adaptive function is introduced in the exponential term, so that the exponential gain term can be adjusted with the change of the system, thus the approach speed of the system is improve. Simulation results show that compared with the traditional SMO, the proposed method can effectively improve the observation accuracy, enhance the robustness, and restrain the chattering phenomenon of the motor double closed-loop control system.

\section{Declarations}

\section{Funding}

This work was supported in part by the Natural Science Foundation of Tianjin City, China, under Grant 18JCYBJC88300 and 18JCYBJC88400.

\section{Conflicts of interests}

The authors declare that they have no conflict of interest

\section{Code availability}

Not applicable

\section{References}

1. Xu, Y.X., Zheng, B., Wang, G., Zou, J.: Current harmonic suppression in dual three-phase permanent magnet synchronous machine with extended state observer. IEEE Trans. Power Electron. 35(11): 12166-12180 (2020).

2. Lee, D.M., Lim, D.C., Ahn, H.J.: Position linearisation scheme for permanent magnet synchronous motor drive of washing machine using low-resolution hall sensors. Electron. Lett. 51(22): 1765-1767 (2015).

3. Lascu, C., Andreescu, G.D.: PLL position and speed observer with integrated current observer for sensorless PMSM drives. IEEE Trans. Ind. Electron. 67(7): 5990-5999 (2020).

4. Marchesoni, M., Passalacqua, M., Vaccaro, L., Calvini, M.: Performance improvement in a sensorless surface-mounted PMSM drive based on rotor flux observer. Control Eng Pract. 96: $104276(2020)$.

5. Zhan, H., Zhu, Z.Q., Odavic, M.: Nonparametric Sensorless Drive Method for Open-Winding PMSM Based on Zero-Sequence Back EMF With Circulating Current Suppression. IEEE Trans. Power Electron. 32(5): 1-1 (2017).

6. Liu, Y.B., Fang, J.K., Tan, K.Z., Huang, B.Y.: Sliding Mode Observer with Adaptive Parameter Estimation for Sensorless Control of IPMSM. Energies. 13(22): 5991 (2020).

7. Campos, P.J, Coria, L.N, Trujillo, L.: Nonlinear speed sensorless control of a surface-mounted PMSM based on a Thau observer. Electr. Eng. 100(1): 177-193 (2018).

8. Nguyen, A.T., Rafaq, M.S., Choi, H.H., Jung, J.W.: A model reference adaptive control based speed controller for a surface-mounted permanent magnet synchronous motor drive. IEEE Trans. Ind. Electron. 65(12): 9399-9409 (2018).

9. Kivanc, O.C., Ozturk, S.B.: Sensorless PMSM drive based on stator feedforward voltage estimation improved with MRAS multiparameter estimation. IEEE-ASME T. Mech. 23(3): 
1326-1337 (2018).

10. Liu, T., Tong, Q., Zhang, Q., Li, L., Wu, Z.: A method to improve the response of a speed loop by using a reduced-order extended kalman filter. Energies. 11(11): 2886 (2018).

11. Zhang., Y., Cheng., X.F.: Sensorless Control of Permanent Magnet Synchronous Motors and EKF Parameter Tuning Research. Math. Probl. Eng. 2016: 1-12 (2016).

12. Chen, Y., Li, M., Gao, Y., Chen, Z.: A sliding mode speed and position observer for a surfacemounted PMSM. ISA trans. 87: 17-27 (2019).

13. Wang, Y., Xu, Y., Zou, J.: Sliding-mode sensorless control of PMSM with inverter nonlinearity compensation. IEEE Trans. Power Electron. 34(10): 10206-10220 (2019).

14. Lian, C.Q., Xiao, F., Gao, S., Liu, J.L.: Load Torque and Moment of Inertia Identification for Permanent Magnet Synchronous Motor Drives Based on Sliding Mode Observe. IEEE Trans. Power Electron. 34(6): 5675-5683 (2019).

15. Jung, T.U., Jang, J.H., Park, C.S.: A back-EMF estimation error compensation method for accurate rotor position estimation of surface mounted permanent magnet synchronous motors. Energies. 10(8): 1160 (2017).

16. Chen, Y., Li, M., Gao, Y.W., Chen., Z.Y.: A sliding mode speed and position observer for a surface-mounted PMSM. ISA Trans. 82: 17-27 (2019).

17. Qian, R.R., Luo, M.Z., Sun, P.: Improved nonlinear sliding mode control based on load disturbance observer for permanent magnet synchronous motor servo system. Adv. Mech. Eng. 10(5): 1 (2016).

18. Liu, K., Gao, H., Ji, H., Hao, Z.: Adaptive sliding mode based disturbance attenuation tracking control for wheeled mobile robots. Int. J. Control Autom. Syst. 18: 1288-1298 (2019).

19. Wang, Y., Hao, W.: An improved synchronous reference frame filter for sliding mode observer position sensorless method of open-winding pm generator system. IEEJ. T Electr. Electr 14(6): 943-947 (2019).

20. Gao, Y., Wu, Y., Wang, X., Chen, Q.: Characteristic model-based adaptive control with genetic algorithm estimators for four-PMSM synchronization system. Int J Control. Autom. 18(6): 1605-1616 (2020).

21. Junejo, A.K., Xu, W., Mu, C.X., Ismail, M.M., Liu, Y.: Adaptive speed control of PMSM drive system based a new sliding-mode reaching law. IEEE Trans. Power Electron. 35(11): 12110$12121(2020)$

22. Mo, L.L., Liu, Y.Q., Zhang, Y.: Sliding mode variable structure control for surface permanent magnet synchronous motors based on a fuzzy exponential reaching law. Math. Probl. Eng. 2019(3): 1-14 (2019).

23. Munoz-Vázquez, A.J., Parra-Vega, V., Sánchez-Orta, A.: Fractional integral sliding modes for robust tracking of nonlinear systems. Nonlinear Dyn. 87(2): 895-901 (2017).

24. Zhan, Y., Guan, J.F., Zhao, Y.F.: An adaptive second-order sliding-mode observer for permanent magnet synchronous motor with an improved phase-locked loop structure considering speed reverse. T.I Meas Control. 42(5): 1008-1021 (2020).

25. Apte, A., Joshi, V.A., Mehta, H., Walambe, R.: Disturbance-observer-based sensorless control of PMSM using integral state feedback controller. IEEE Trans. Power Electron. 35(6): 60826090 (2019).

26. Liang, D.L., Li, J., Qu, R.H., Kong, W.B.: Adaptive Second-Order Sliding-Mode Observer for PMSM Sensorless Control Considering VSI Nonlinearity. IEEE Trans. Power Electron. 33(10): 8994-9004 (2018).

27. Wang, L.A., Du, H., Zhang, W.J., Wu, D., Zhu, W.W.: Implementation of integral fixed-time sliding mode controller for speed regulation of PMSM servo system. Nonlinear Dyn. 102(1): 1$12(2020)$.

28. Selvam, D., Subbaian, S., Ananthan, B., Rameshkumar, T.: T-source inverter-based sensorless speed control for permanent magnet synchronous motor. J Test Eval. 48(2): 1745-1768 (2020). 
Figures

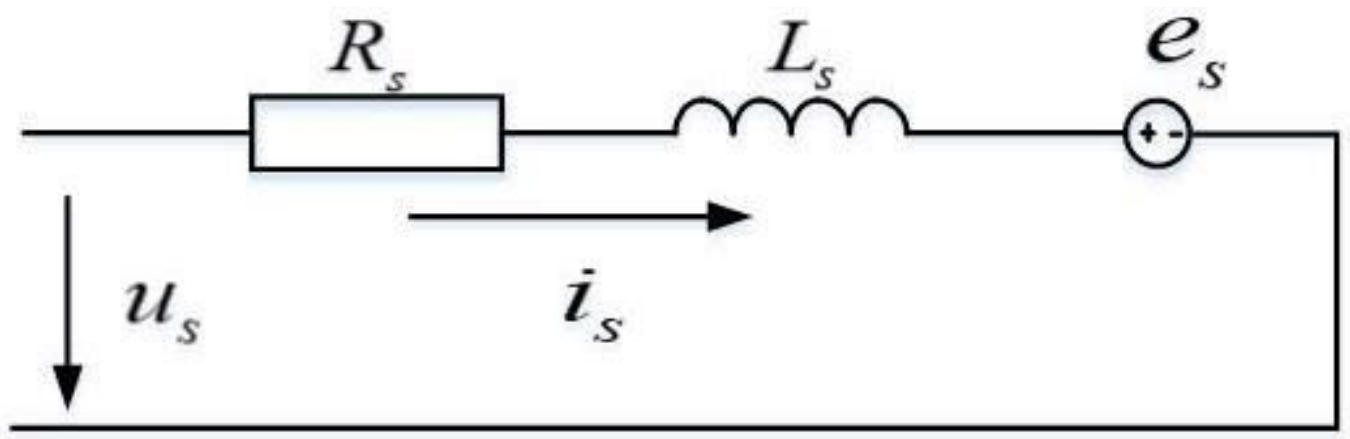

Figure 1

The voltage equivalent circuit diagram of three-phase SPMSM

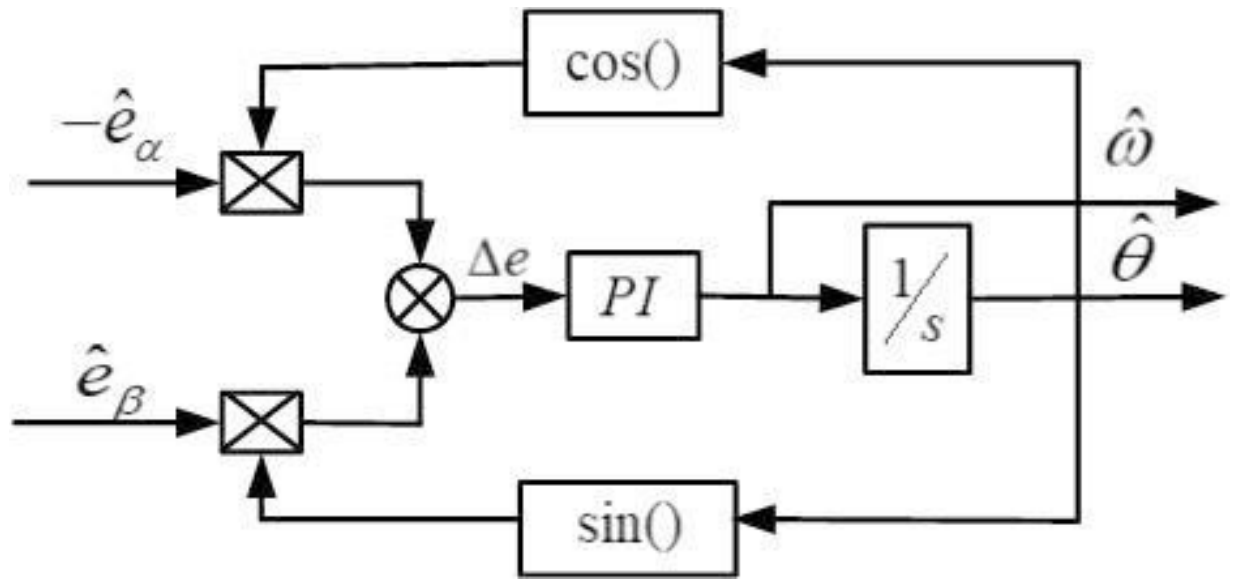

Figure 2

Block diagram of the PLL

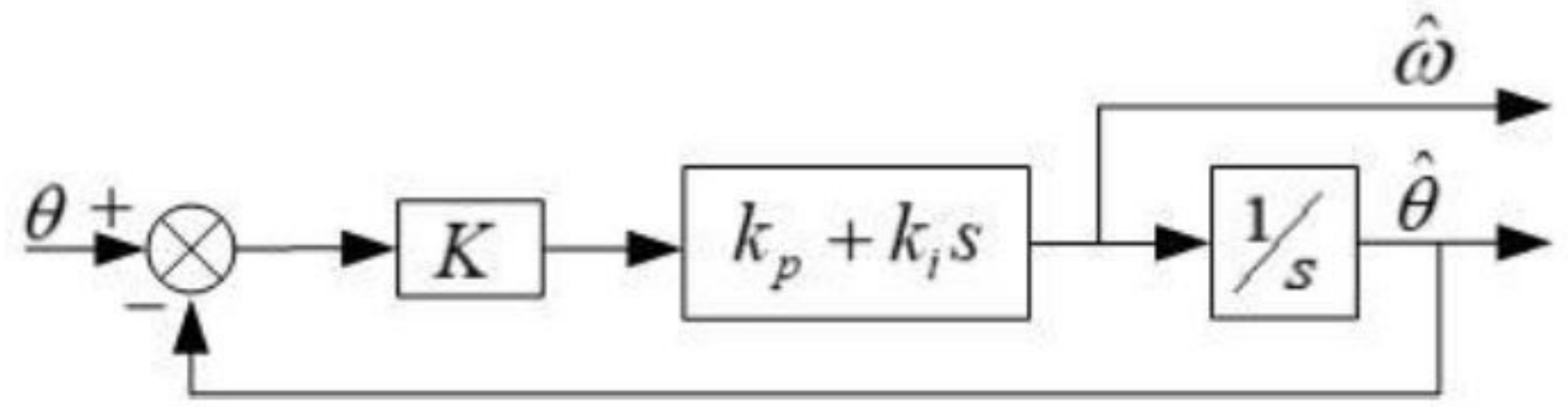

Figure 3

Equivalent structure diagram of the PLL 


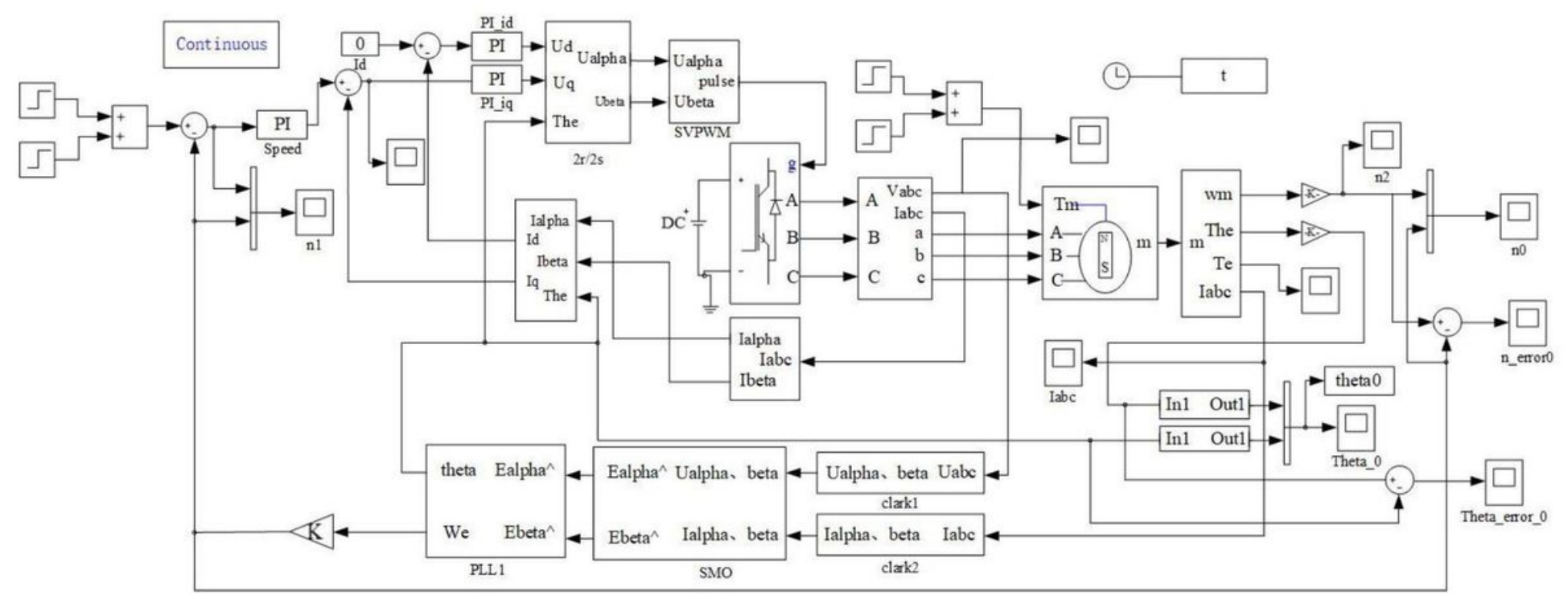

Figure 4

Simulation model of sliding mode observer system for SPMSM
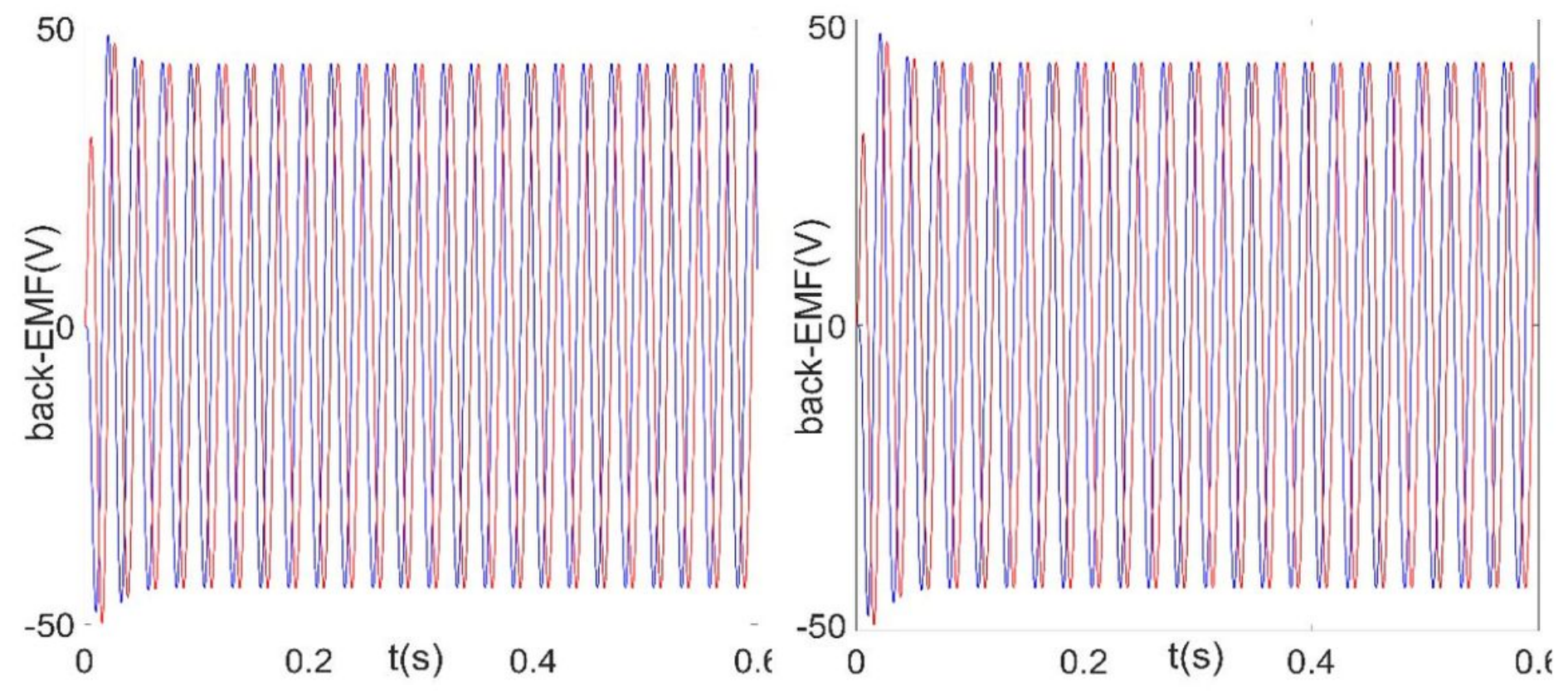

(a) The back-EMF of high-order SMO

(b) the back-EMF of traditional SMO

Figure 5

Tracking performance of two SMOs $₫$ No load torque $\rrbracket$ 


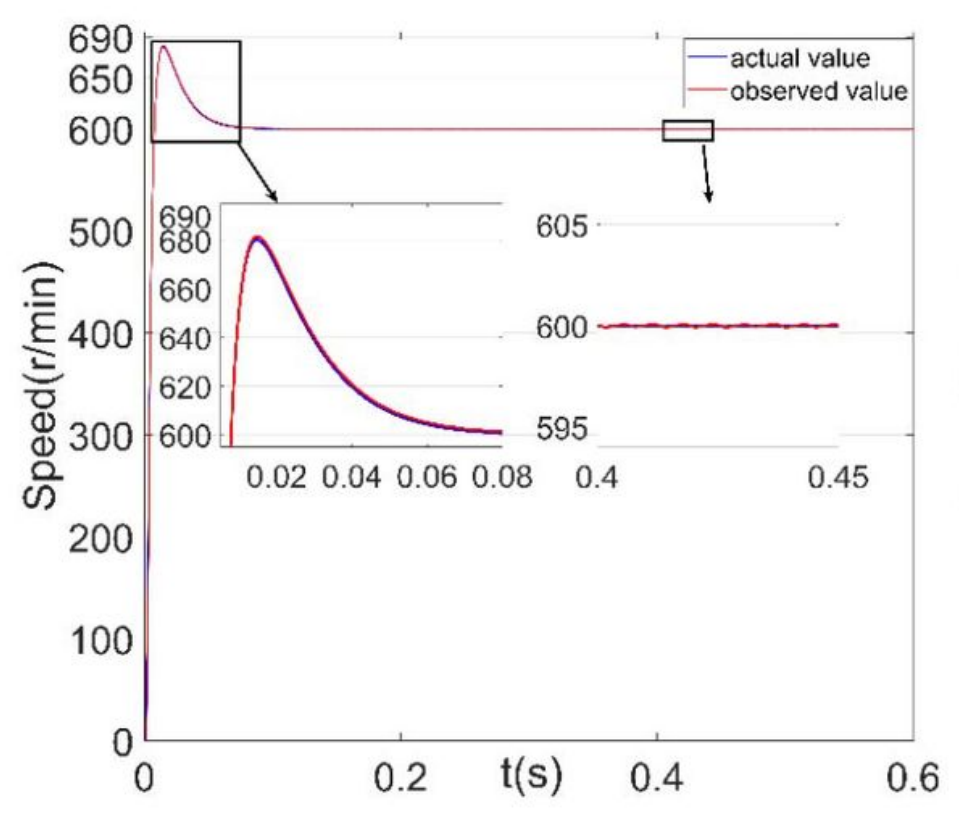

(a) speed tracking of high-order SMO

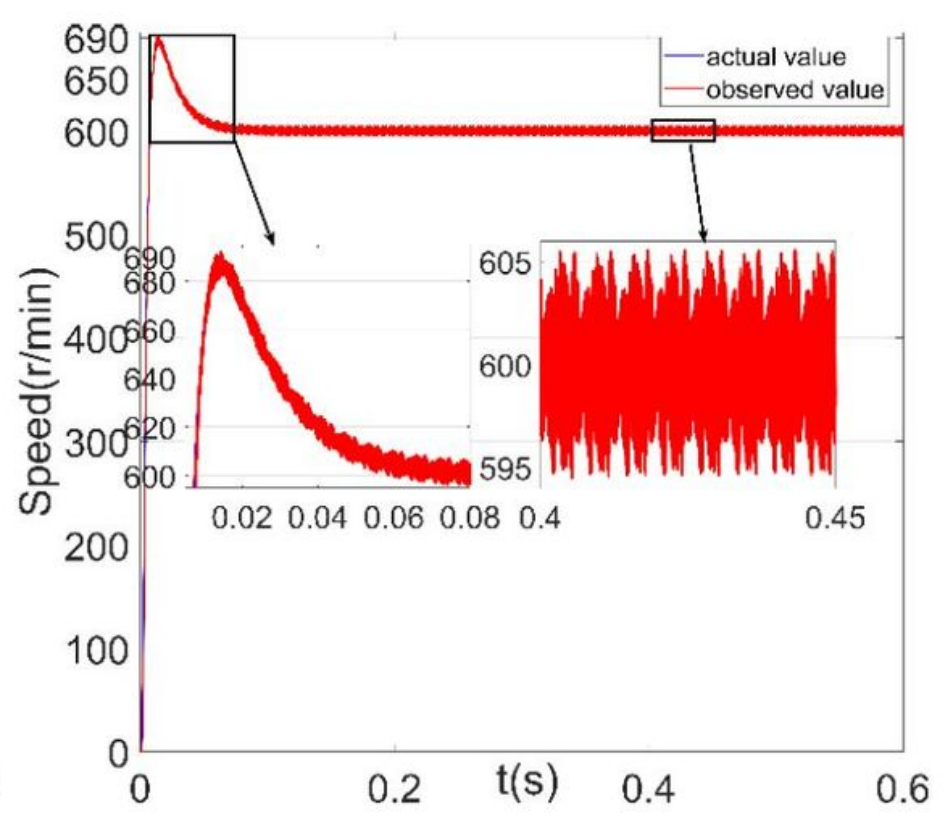

(b) speed tracking of traditional SMO

\section{Figure 6}

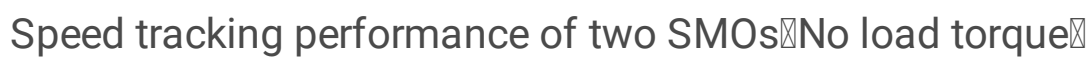

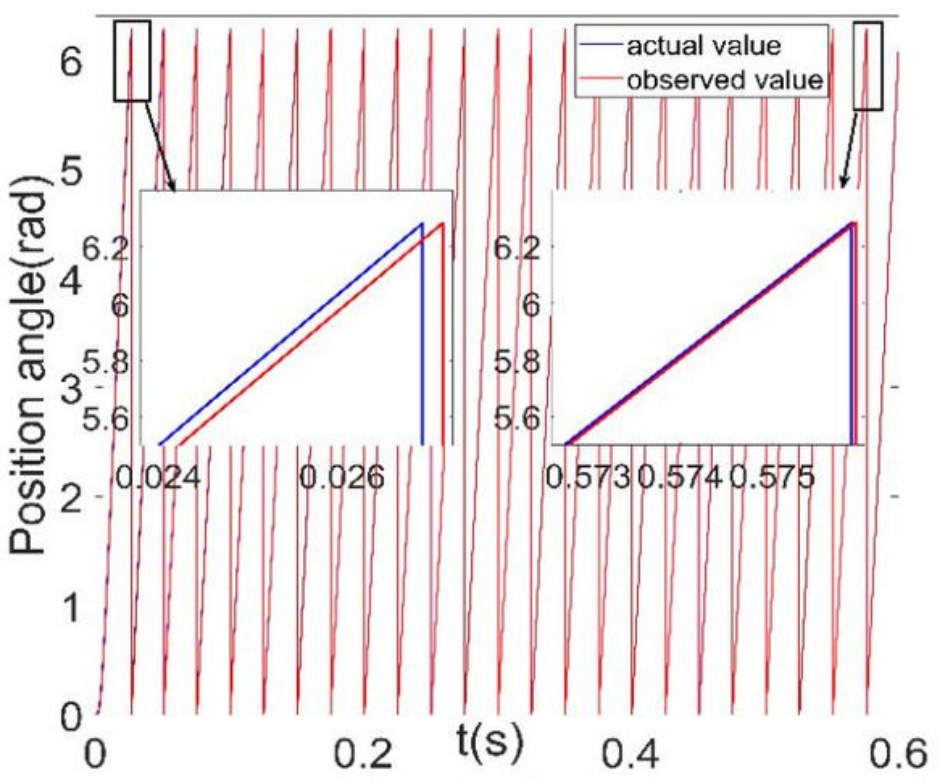

(a) position tracking of high-order SMO

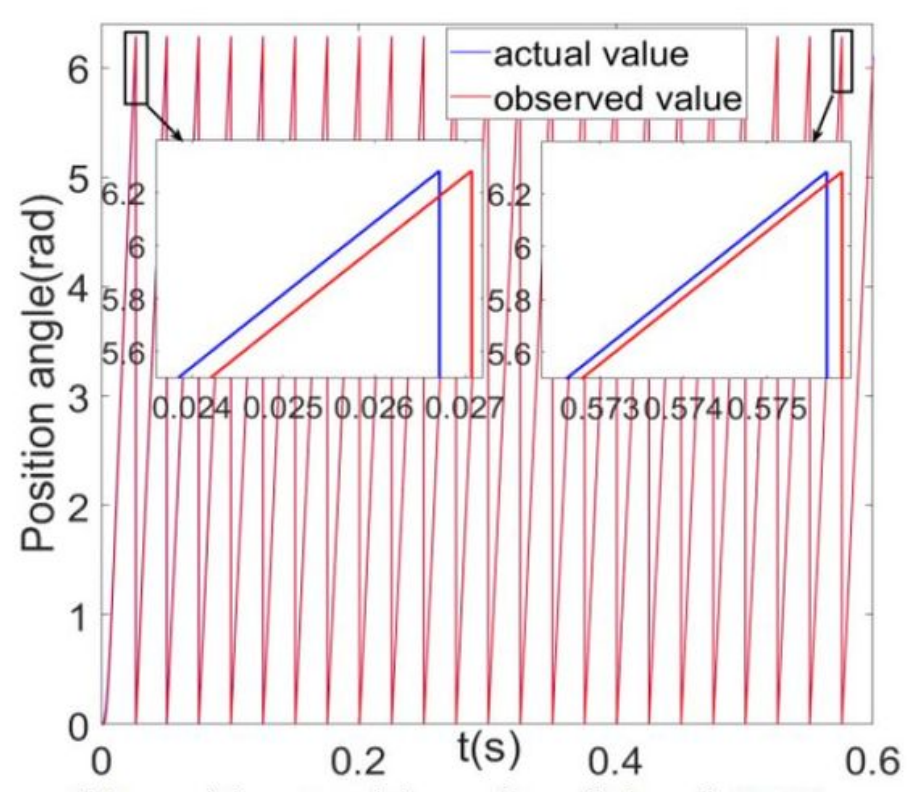

(b) position tracking of traditional SMO

\section{Figure 7}

Tracking performance of two SMOs $₫$ No load torque 


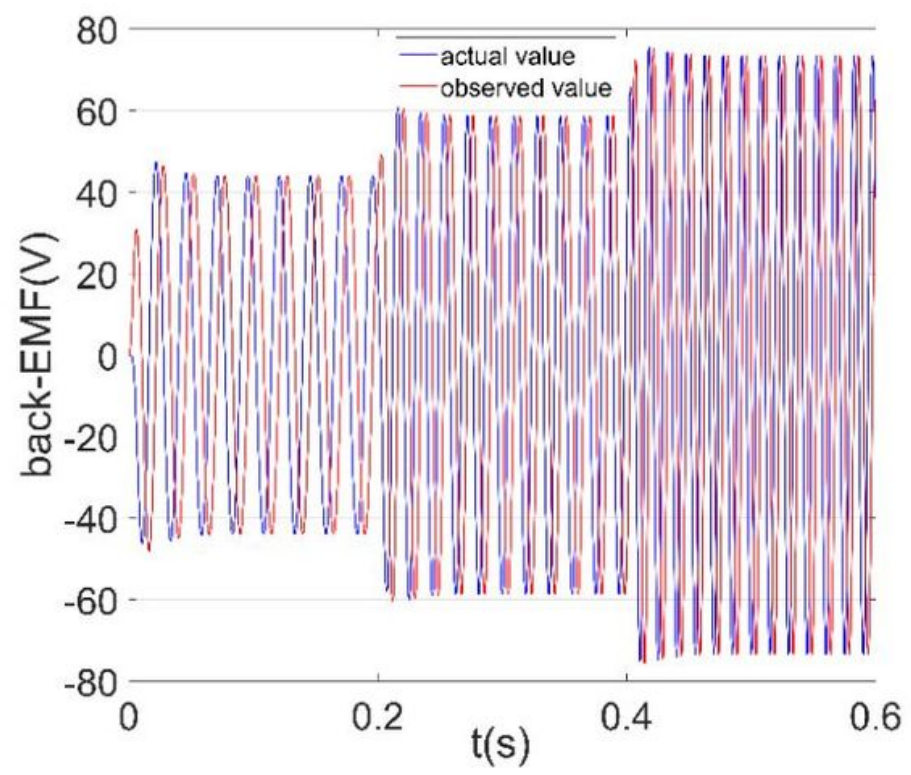

(a) back-EMF of high-order SMO

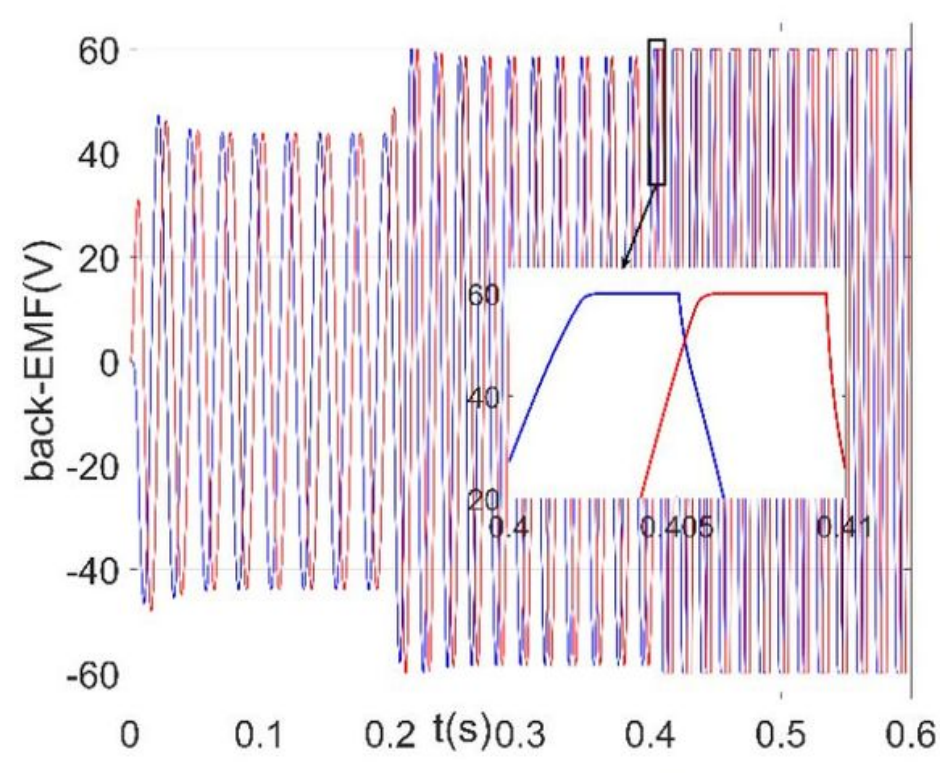

(b) back-EMF of traditional SMO

\section{Figure 8}

Back-EMF tracking of two SMOs(Speed step up)

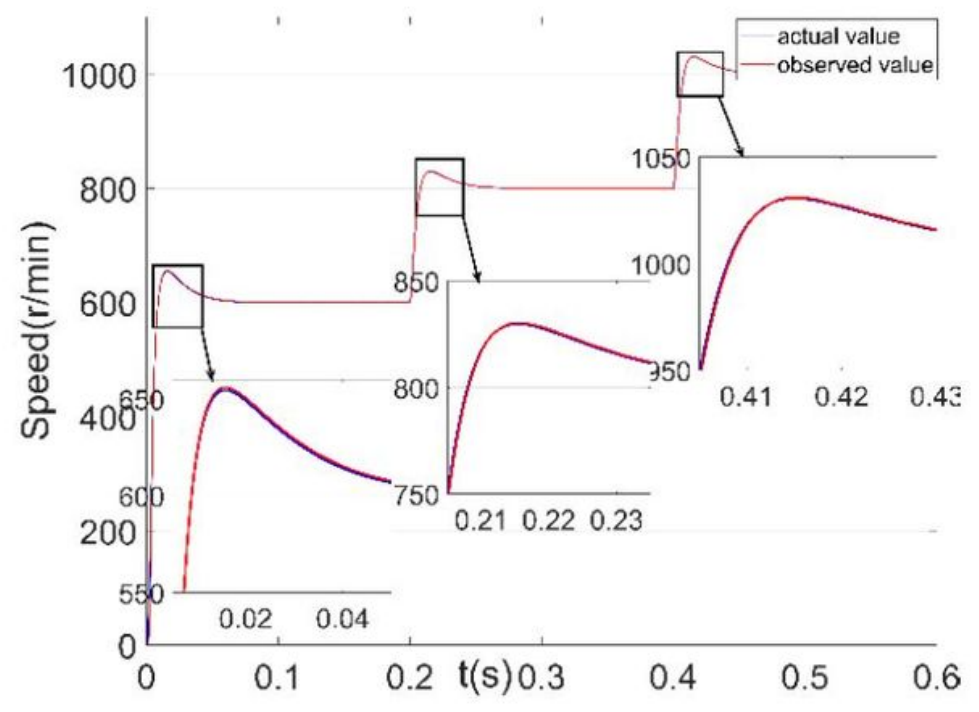

(a) Speed tracking of high-order SMO

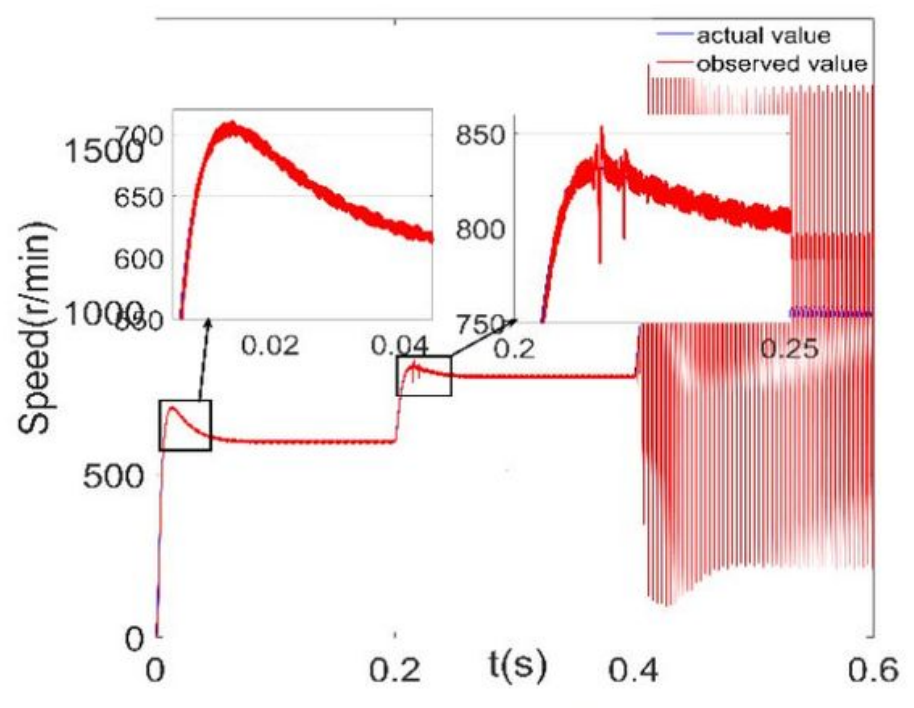

(b) Speed tracking of traditional SMO

\section{Figure 9}

Speed tracking of two SMOs(Speed step up) 


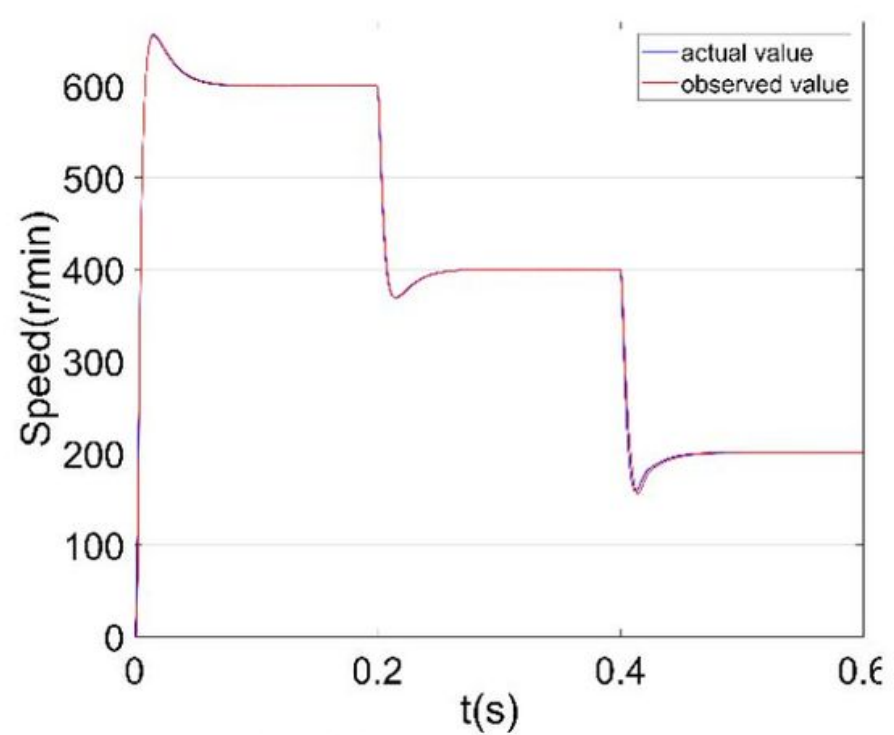

(a) Speed tracking of high-order SMO

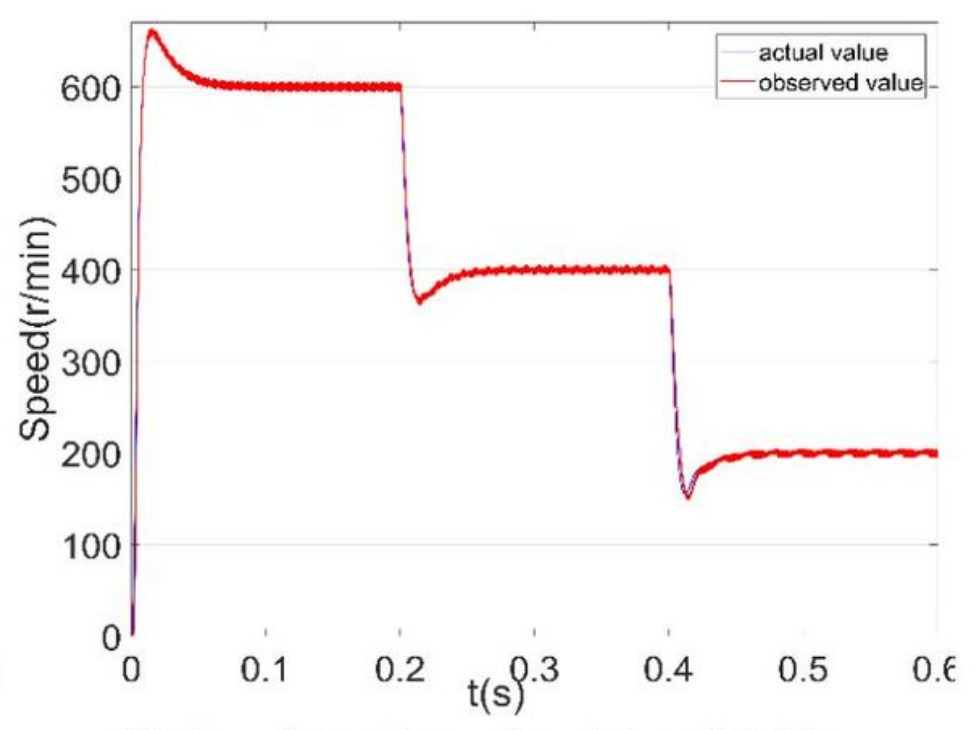

(b) Speed tracking of traditional SMO

Figure 10

Speed tracking of two SMOs(Speed step down)

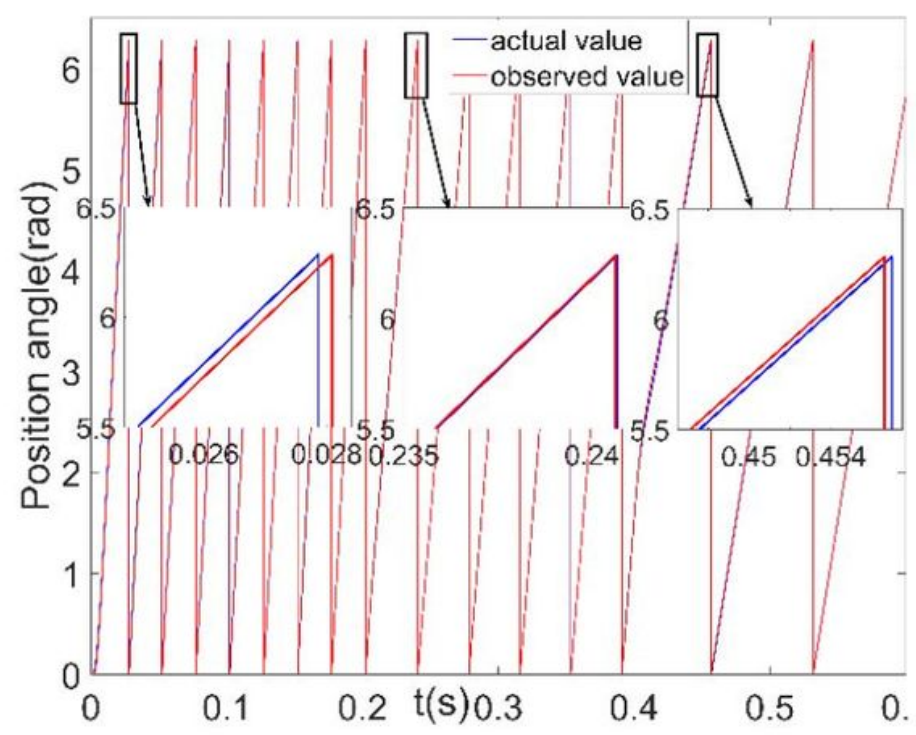

(a) Position of high-order SMO

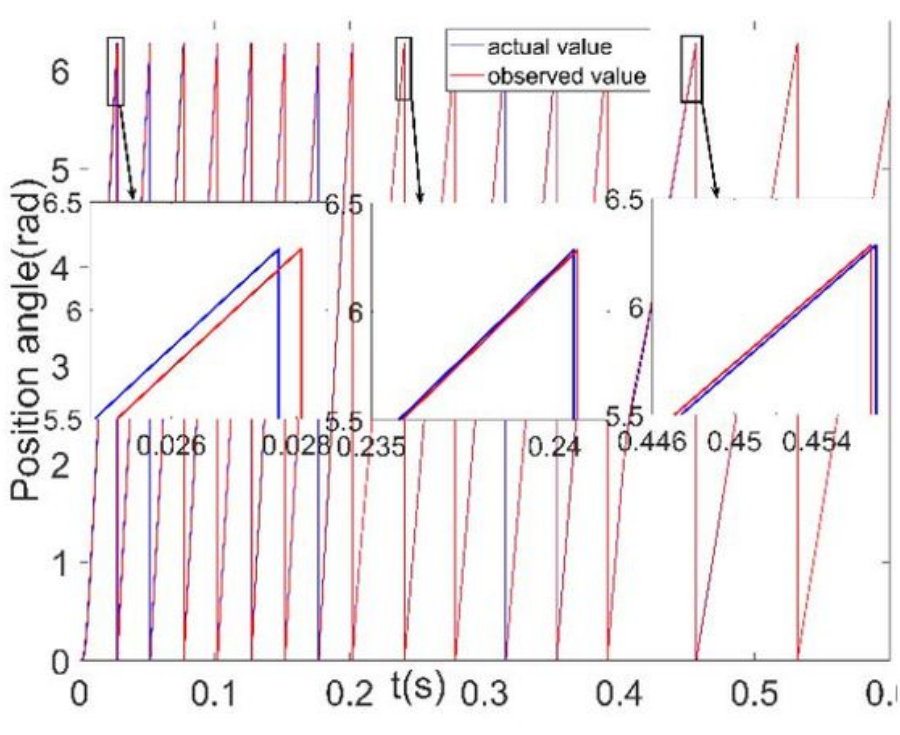

(b) Position tracking of traditional SMO

\section{Figure 11}

Position tracking of two SMOs(Speed step down) 


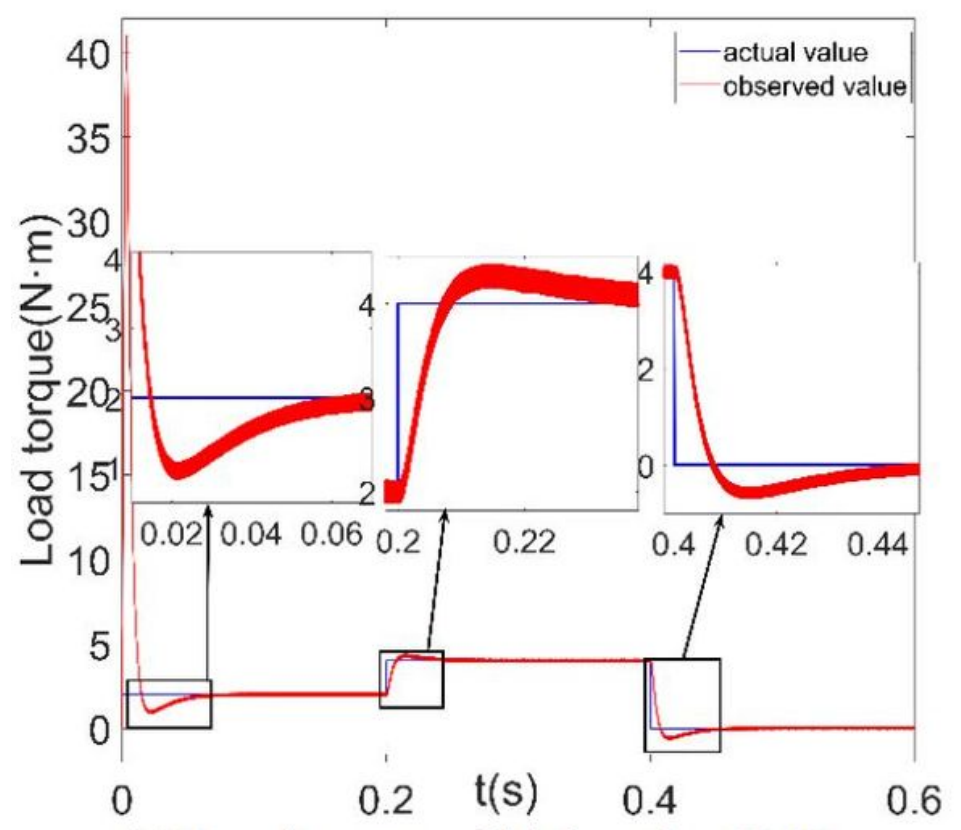

(a) Load torque of high-order SMO

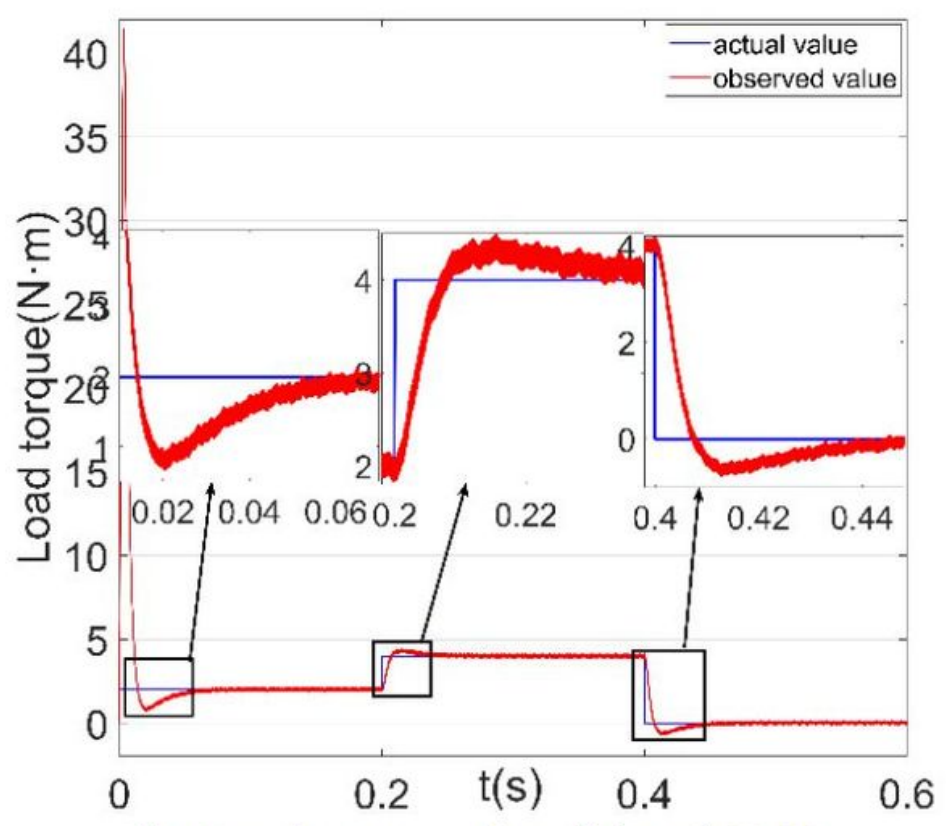

(b) Load torque of traditional SMO

Figure 12

Tracking performance of two SMO(Load torque)

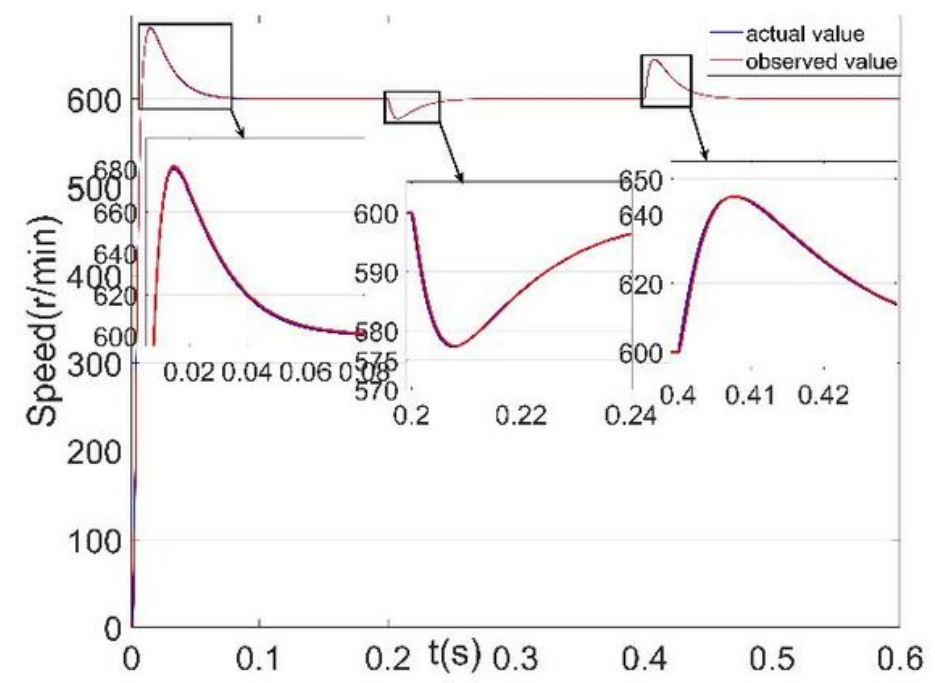

(a) Speed tracking of high-order SMO

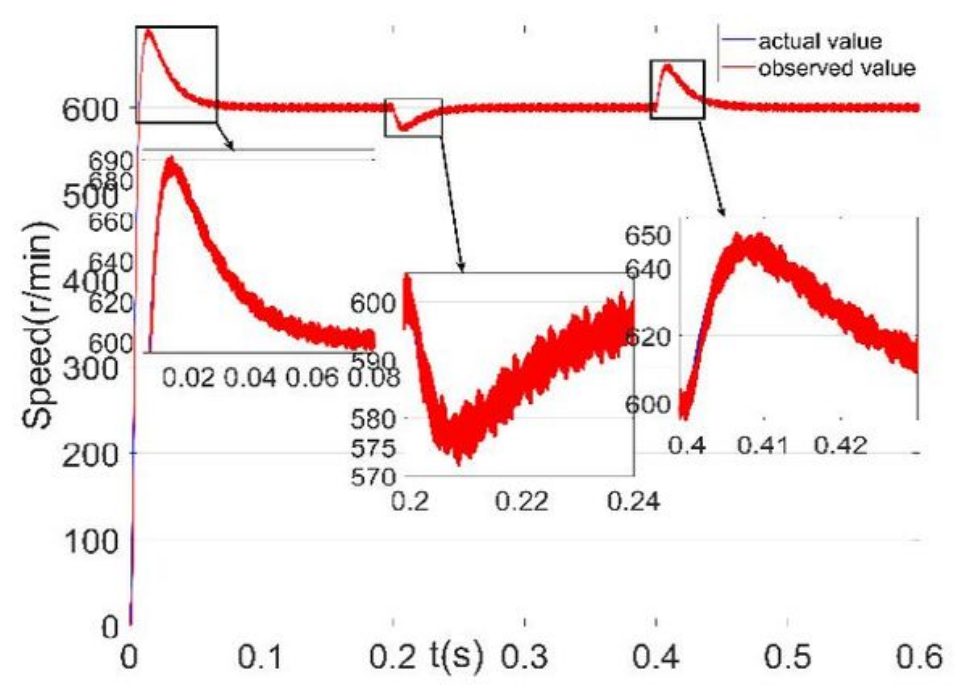

(b) Speed tracking of traditional SMO

\section{Figure 13}

Speed tracking performance of two SMO(Load torque) 


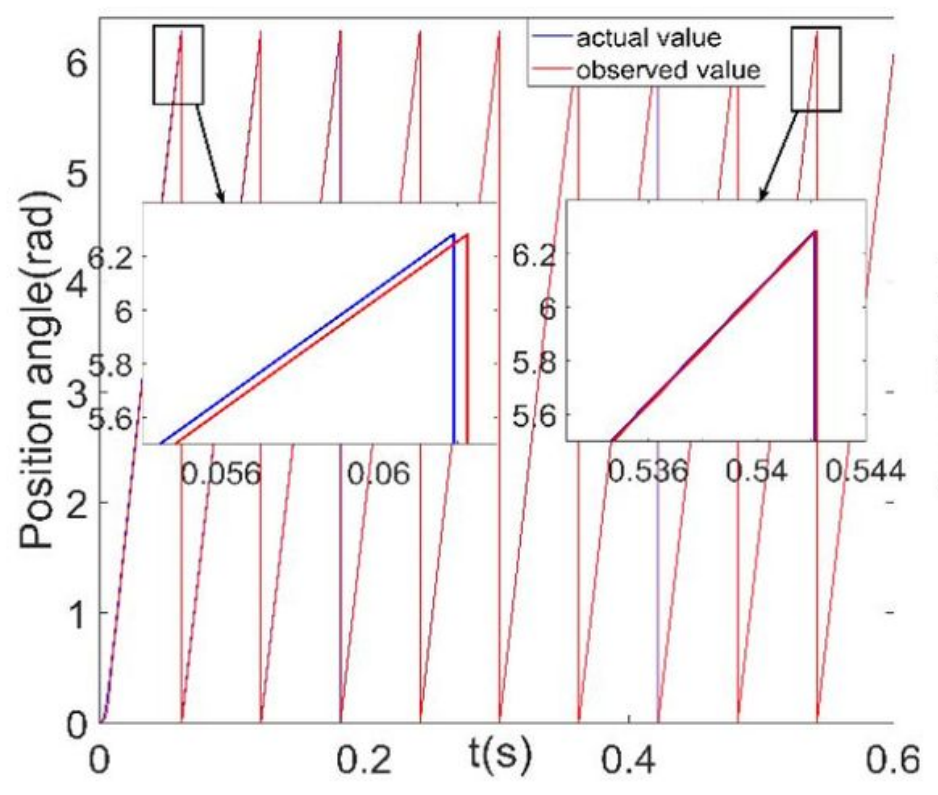

(a) Position tracking $\left(R_{s}=4.3125 \Omega\right)$

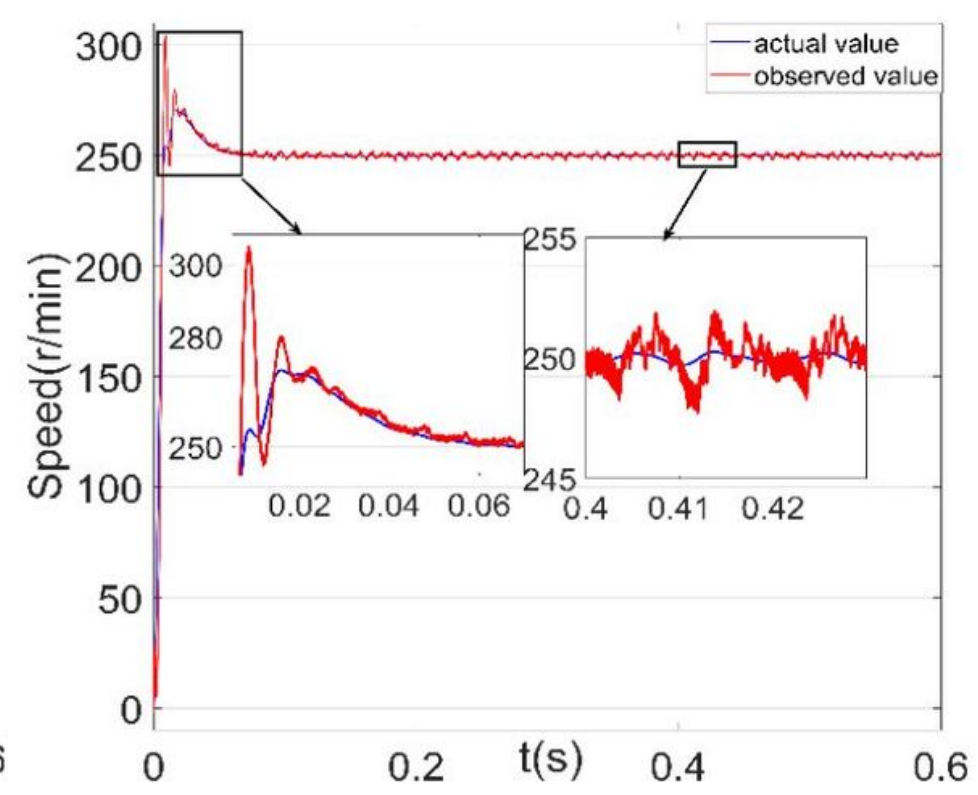

(b) Speed tracking $\left(R_{S}=4.3125 \Omega\right)$

\section{Figure 14}

Tracking performance of high-order SMO(resistance increase)

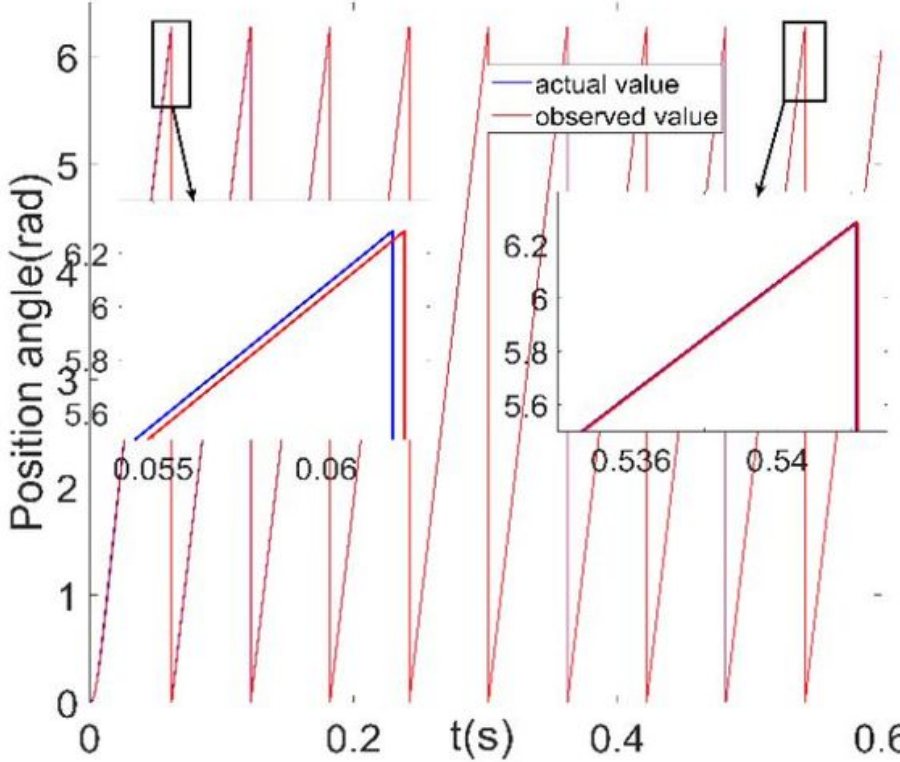

(a) Position tracking $\left(R_{S}=1.4375 \Omega\right)$

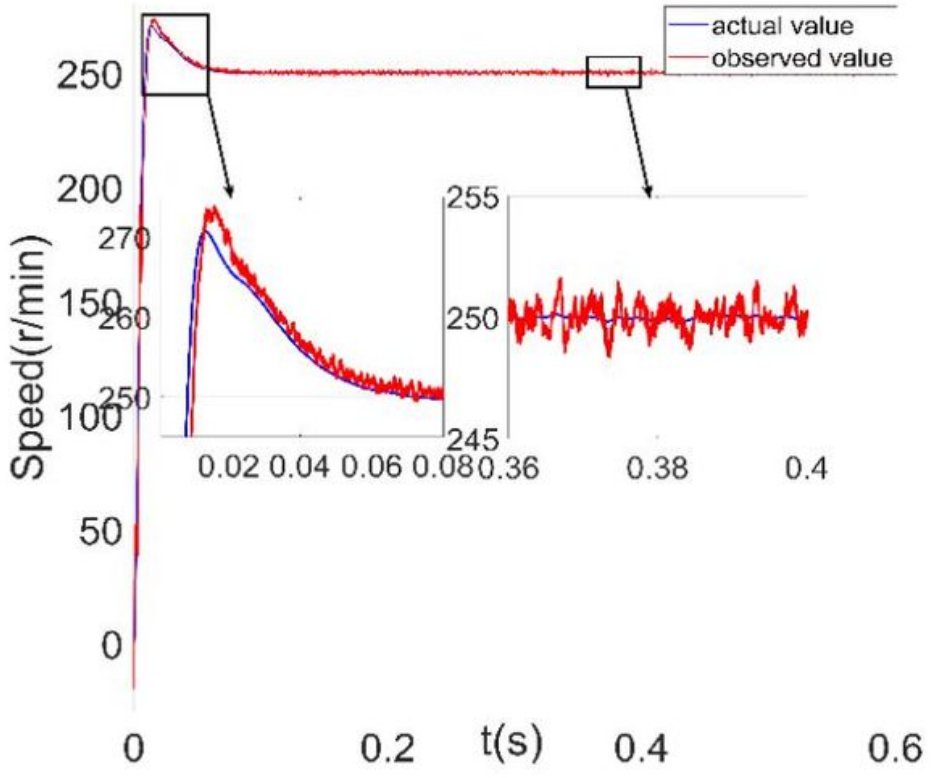

(b) Speed tracking $\left(R_{S}=1.4375 \Omega\right)$

\section{Figure 15}

Tracking performance of high-order SMO(resistance decreases) 